\title{
On Dinosaur Reconstruction: An Introduction to Important Topics of Paleontology and Dinosaurs
}

\author{
Georgios A. Florides $\mathbb{(}^{\circ}$, Paul Christodoulides \\ Faculty of Engineering and Technology, Cyprus University of Technology, Limassol, Cyprus \\ Email: paul.christodoulides@cut.ac.cy
}

How to cite this paper: Florides, G.A. and Christodoulides, P. (2021) On Dinosaur Reconstruction: An Introduction to Important Topics of Paleontology and Dinosaurs. Open Journal of Geology, 11, 525-571. https://doi.org/10.4236/ojg.2021.1110028

Received: September 11, 2021

Accepted: October 26, 2021

Published: October 29, 2021

Copyright (อ 2021 by author(s) and Scientific Research Publishing Inc. This work is licensed under the Creative Commons Attribution-NonCommercial International License (CC BY-NC 4.0). http://creativecommons.org/licenses/by-nc/4.0/ (c) (i) (8) Open Access

\begin{abstract}
Many people may be interested in Paleontology since the subject allows for large amounts of imagination and freedom in the creation of scenes. Dinosaurs draw the biggest interest because of their diversity in peculiar forms and often unusually large size of many species. There are people like artists who help the field paleontologists to describe, interpret and reconstruct fossils, and others that create drawings, restorations, sculptures and, most recently, computer animations for science, art and joy. To this end, a successful professional should have specific knowledge that will allow them to produce high-quality work. The current paper aims at: 1) providing knowledge on various topics of Paleontology, in order to understand the time scale of life on earth, its evolution and diversity; 2) generating appreciation for the evolution of climatic conditions, continental plates and movement and the Mesozoic environment in which dinosaurs evolved; 3) offering an understanding of scientific nomenclature used in Paleontology, and interpretation of drawings and meanings; 4) helping one to realize how scientists extract information from bones, tracks, eggs, embryos and other remains; 5) examining the physiology of dinosaurs, their metabolism, behaviors, growth rates estimated lifetime and diet; and 6) leading to the understanding of the relations between different dinosaur species and how Paleontologists complete missing parts from uncomplete skeletons. Examining the evolution of life, we observe that life began about 3.8 billion years ago in the deep sea. The first simple animals such as worms and jellyfish appeared in the oceans around 600 mya. The crust of the earth continuously moves to produce changes in the land masses and changes in the climatic conditions that affect the evolution of life. The life of the earth is divided into geological eras. At the end of each geological era, a major event of extinction occurred, which every time obliterated important groups of life. Dinosauria was one of the most successful clades of animals
\end{abstract}


that lived on terrestrial ecosystems for over 160 million years, but was extinct at one of the major extinction events 66 mya. The remains of animals allow scientists and artists to recreate their forms usually in great detail and extract a lot of information about their lives. The paper describes in detail how and where to find information and explains how to interpret them in order to understand the meanings. The paper presents all the above in a simplified way giving the required knowledge without using difficult scientific terms and provides the essential knowledge to the interested person to appreciate the science of Paleontology.

\section{Keywords}

Extinct Animals, Geological Time Chart, Skeletal Reconstruction, Dinosaur Modeling

\section{Introduction}

It is a fact that many people's profession is to present to the public an aspect of the prehistoric world such as, for example, animals of that era. Many of such presentations are usually scientifically sound, especially if offered by artists working under the direct supervision of paleontologists. However, some other presentations happen to be inaccurate and usually exaggerate the characteristics of animals or place them in inappropriate environments. Additionally, a lot of interested scientists coming from unrelated disciplines have a vague or no idea about the prehistoric world.

The current work is a first in a series of articles that aim to present all the necessary information concerning the science of Paleontology, without using difficult scientific terms, thus educating the interested reader on important topics of this science. The desired outcome is to make one (artist or scientist) appreciate Paleontology and enable them to continue their search on specific topics related to dinosaur reconstruction.

Associated scientists and artists always offer a helping hand to paleontologists in describing and interpreting fossils. With their work, be it drawings, restorations, sculptures and, more recently, computer animations, they present an organism in a very lively manner. As the remains of an organism found on a site are usually incomplete, various details must be completed by experts, leading to a complete visualization or reconstruction of the organism. The experts also help in the visual depiction of the animal, offering details about the possible anatomy, external appearance, stature and movement.

To represent an animal as accurately as possible, one should know the fundamentals of Paleontology that will enable them to have an insight into the animal's details and its environment. Additionally, for the realistic reconstruction of an animal, it is necessary to obtain all the known relevant information about the animal and fill in the missing information in a scientific manner. There will 
usually be a published paper in a scientific journal describing the animal's remains, from which one can make a start.

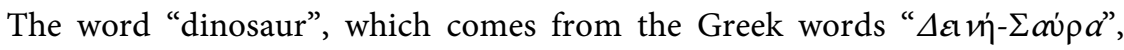
actually means "terrible, dreadful or fearful lizard or reptile". This name was given by Sir Richard Owen (1804-1892) who was an anatomist working in the Natural History section of the British Museum. Based on his study of Megalosaurus, Iguanodon and the ankylosaur Hylaeosaurus [1], Owen first announced the name of the new group of animals at a meeting of the British Association for the Advancement of Science, in 1841. In this way, a new group of animals called "Dinosauria" was created, which described the splendor and size of the animals.

From the very beginning, the first dinosaur findings caught the world's attention. People were fascinated by the idea that there was a prehistoric world with real living creatures, so enormous and powerful and so bizarre that it was beyond anyone's wildest imagination. Subsequent findings confirmed that dinosaurs existed on all continents, with each group evolving individually according to the specific conditions of its environment. Dinosaurs appeared in the late Triassic period about 225 million years ago (mya). At the same time, the mammal-like reptiles, which then ruled the earth, declined unexpectedly and were replaced first by archosaurs and then by real dinosaurs [2]. By the Triassic, all the major land regions of the world were united into one single supercontinent called Pangaea, while around the end of the Triassic and the beginning of the next period (Jurassic); Pangaea began to fragment in pieces [3]. After another major event at the end of the Cretaceous period (about 66 mya), the dinosaurs became extinct forever. During their 160 million years of ruling, dinosaurs showed remarkable evolutionary activity.

Dinosaurs can be studied through their preserved remains or traces, called fossils. Fossils may consist of skeletal remains (bones, teeth), may contain traces of skin, feathers or even (as recently reported) soft tissues. Usually, the original material is not preserved but mineralized in various processes. In some rare cases organisms, such as plant matter, insects, spiders, annelids, etc., can be found trapped inside amber. In other cases, the remainders of the original organism dissolve completely, leaving a cavity that is filled with other material in a later state, forming a cast. Fossils can also consist of marks left by organisms while they were alive, such as animal traces or faeces (coprolites). Finally, past life may leave some markers that are biochemical in nature and can now be detected.

Dinosaur living style presentations and art has been with us for more than a century and a half. The first dinosaur sculptures in the world were presented in 1854 [4]. These were created by Waterhouse Hawkins, an English sculptor and natural history artist who constructed life-size models of dinosaurs and other extinct animals in London's Crystal Palace Park. This work (Figure 1) is still on display at Sydenham Hill, next to the Crystal Palace National Sports Centre. More recently, many famous paleontologists and artists, such as Robert $\mathrm{T}$. Bakker, Stephen A. Czerkas, John Sibbick, Gregory S. Paul and many others have produced illustrations for books, sculptures, and so on. Moreover, new art is 


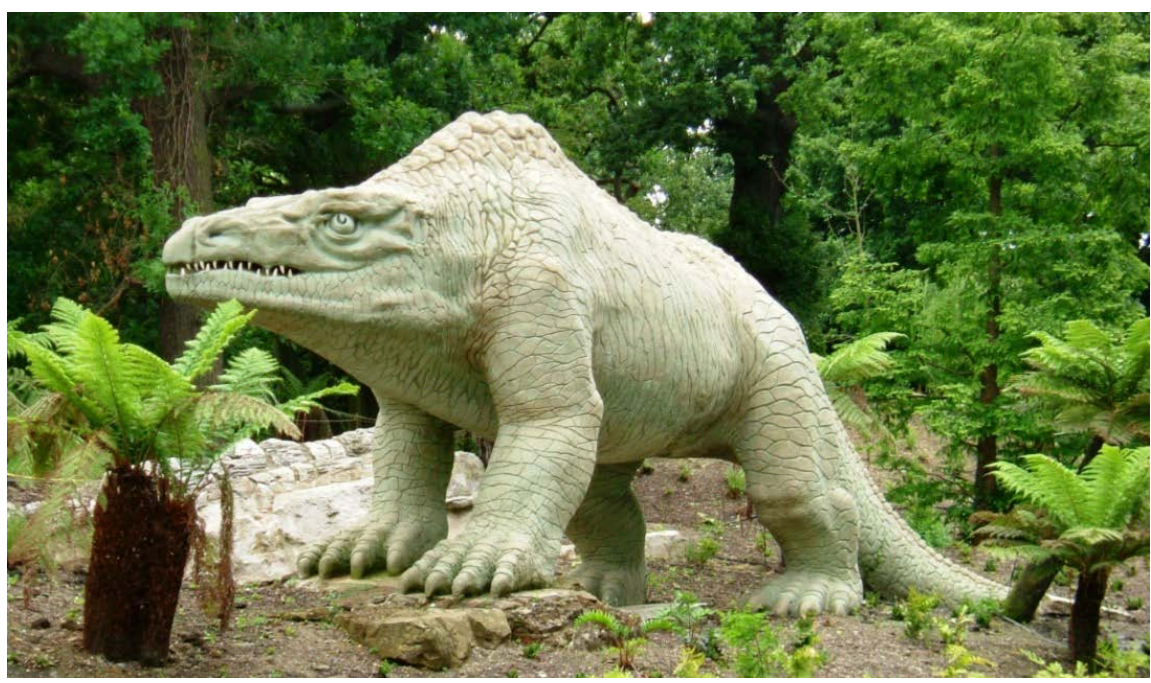

Figure 1. A renewed life-size model of iguanodon was created by Waterhouse Hawkins who created the model according to the then knowledge (1854). Today's reconstruction would be quite different.

the creation of dinosaur robots, by special companies, in real size with realistic appearance and movement, the so-called animatronic dinosaurs. These technological machines are now on display in museums and parks. Finally, 3D computer models of dinosaurs, created and viewed with sophisticated software that offer many advantages, are also available for filmmaking and scientific studies.

The present paper introduces the reader to the world of Paleontology. The study presented here addresses a wide range of topics of science. The current Review can serve as a brief scientific/educational guide for scientists and artists, giving them important knowledge that can enable them to gain a deeper insight and appreciation of any particular paleontological topic. Reviews on paleontological issues indeed exist in the literature, but none deals comprehensively with all the important topics of Paleontology. The paper is written in a way that, we believe, is appealing to the widest possible readership, and, hence, can contribute to the further penetration of Paleontology in wider fields. It will also motivate people to interact with Paleontology, diluting any existing myths about dinosaurs. Section 2 presents the methodology followed, while all relevant topics are reviewed in Section 3.

\section{Materials and Methods}

The current work presents paleontological topics that are found in the literature and can serve as a short and simple scientific guide.

Before trying to bring to life (or reconstruct) any extinct animal, one must obtain all useful information about the animal's remains as detailed in relevant papers and books available in the literature. It is crucial that for successful reconstruction, the interested person should: 1) be familiar with the relevant nomenclature to understand the written information, 2) be able to appreciate the extinct environments in which the animal spent its life, 3) have knowledge of 
which forms are relevant to the specific animal in order to add any missing characteristics, 4) gain insight into the animal's behavior (posture, movement, growth, feeding, reproduction) and many others.

Because of the wide field of information needed for the purpose stated above, a complete review of all existing knowledge on every individual subject would be a monumental task, leading to voluminous writings. To keep the paper handy and informative, we instead focus on the knowledge found in basic books of general Paleontology, including knowledge found in journals to give new updates. Where needed we have included tables, charts and maps that are freely available in the Web to the reader, either generated by open software or updated regularly to represent the present knowledge?

Also, in the paper it is mentioned whether certain information has been questioned or there is no general consensus on the subject, in order to alert the reader. Many questions in Paleontology remain open, but the gaps narrow as new information comes to light with new findings and new tools and methods that technology provides.

After a thorough selection of books and journal papers (found by searching every topic that is included here individually in electronic libraries), we decided to include those listed in the references because of their comprehensive and current information capacity, pioneering grade, clarity and simplicity.

The paper offers important knowledge that can help one gain a deeper insight and appreciation for any particular subject of Paleontology. Therefore, the paper can contribute to the further penetration of Paleontology in wider fields.

The subjects covered are presented in the sequel (Section 3) and include: geological time-chart, life on earth, paleogeography and climate, animal classification, body symmetries, skeletal nomenclature, fossil formation, posture of dinosaurs, dinosaur tracks, dinosaur metabolism, dinosaur reproduction, dinosaur age estimation, lifespan and growth rate of dinosaurs, dinosaur diet and feeding.

\section{Results}

This section presents the scientific background on specific subjects of Paleontology.

\subsection{The Geological Time-Chart}

In order to reconstruct the geological history of the earth and to understand the evolution of life, it is critical to date the rocks. The rocks are formed in layers, with the oldest one at the bottom and the newest one on top. To date them, geologists use either the absolute or the relative dating method. Absolute dating shows the time from the present-day that the layer was formed. For this type of dating, radioisotopic methods are used for volcanic rocks implanted in the same strata (sedimentary rock layers) as the fossils [5].

The most reliable techniques applied so far in dating strata of dinosaur-bearing include K-Ar with uncertainties (2 standard deviations) of $2 \%-4 \%, 40 \mathrm{Ar} / 39 \mathrm{Ar}$ 
with uncertainties of less than $0.5 \%, \mathrm{Rb}-\mathrm{S}$ with uncertainties (2 standard deviations) of typically $1 \%-5 \%$ and U-Pb with uncertainties as low as $1 \%$ [6].

Relative dating, on the other hand, does not estimate the time from the present-day, but places the events in the correct order by comparing the strata of the earth that contain distinct fossils. In the early 1800s in Western Europe, the civil engineer William Smith observed that a given stratum usually contained distinct fossils. Distinct fossils have been found in large areas, even when the composition of the enclosing rock is different. The science of using the fossil content to identify and distinguish strata was therefore born and is called Biostratigraphy. Based on the above, Smith constructed and published the first geological map of England [7].

The two procedures are kept distinct, as not all types of rocks and fossils can be dated. Ancient life that cannot be directly dated is related to age-dated material with the techniques of relative dating. The geological timescale (Figure 2, [8]) is divided into eras, periods, epochs and ages, and associated subdivisions (upper and lower).

\subsection{Life on Earth}

The sequence of rocks and the life entrapped into them has led science to the conclusion that all life on earth originates from a common ancestor. Theoretically, biological evolution started from a simple organism and expanded to an enormous variety of life. Evolution refers to the change of inherited characteristics, thus causing small changes in a population from one generation to the next and in large-scale evolution, where different species descend from a common ancestor for many generations. The father of "evolution" is Charles Darwin who, in 1859, established the Theory of Evolution by natural selection, as described in his book "On the Origin of Species" [9]. By observing and studying past and present life forms, evolutionary scientists construct "family trees", where one can explore evolutionary change and relationships. An example of such a tree is shown in Figure 3.

The hypothesis that all life is related and the relations among organisms lead to the conclusion that life can be divided into three major clades (domains) which are: The Archaea, the Bacteria and the Eukaryota.

It is worth noting that the complete life tree shows that maximum diversity in anatomical forms was reached very early in the multicellular life history. This was followed by the extinction of most of these initial experiments, but the surviving lines successfully developed many new species and not new anatomies.

There exist more species today than ever before, although fewer basic anatomies remain (Figure 4).

Examining the evolution of life in the past, we observe that life began about 3.8 billion years ago in the deep sea. Stromatolites, rocklike mounds, formed by colonies of bacteria, represent the oldest evidence of life on earth and date back 3.5 billion years [11]. The first simple animals such as worms and jellyfish appear in the oceans around 600 mya. At 520 mya many new kinds of animals 


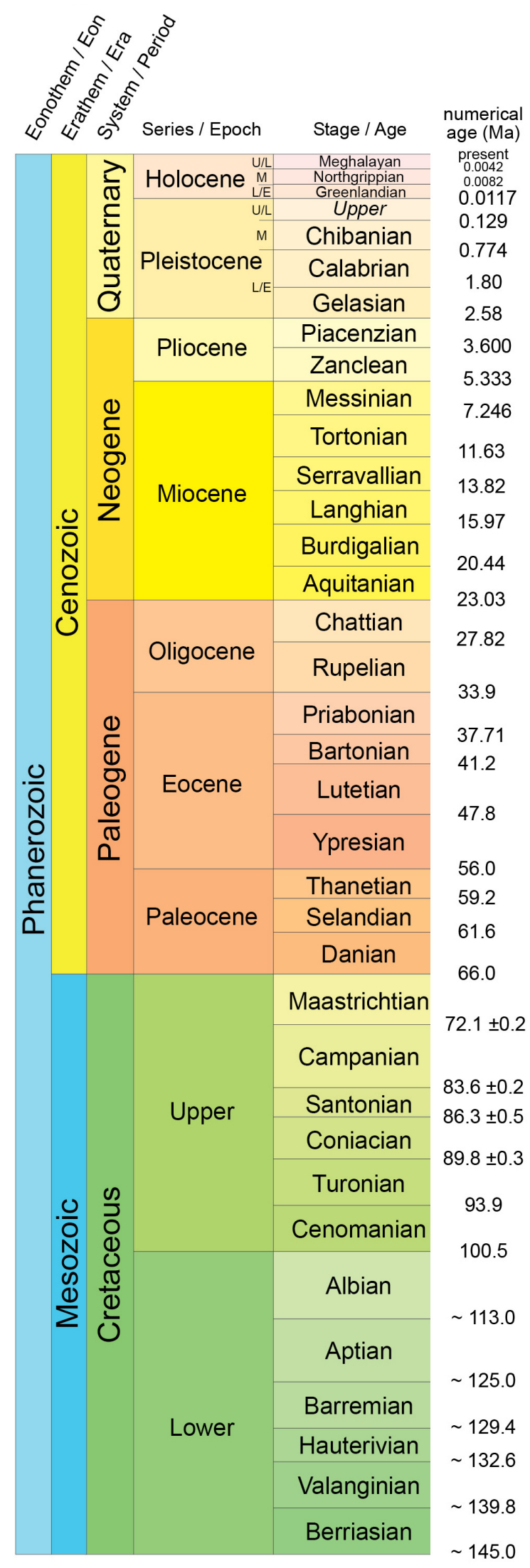

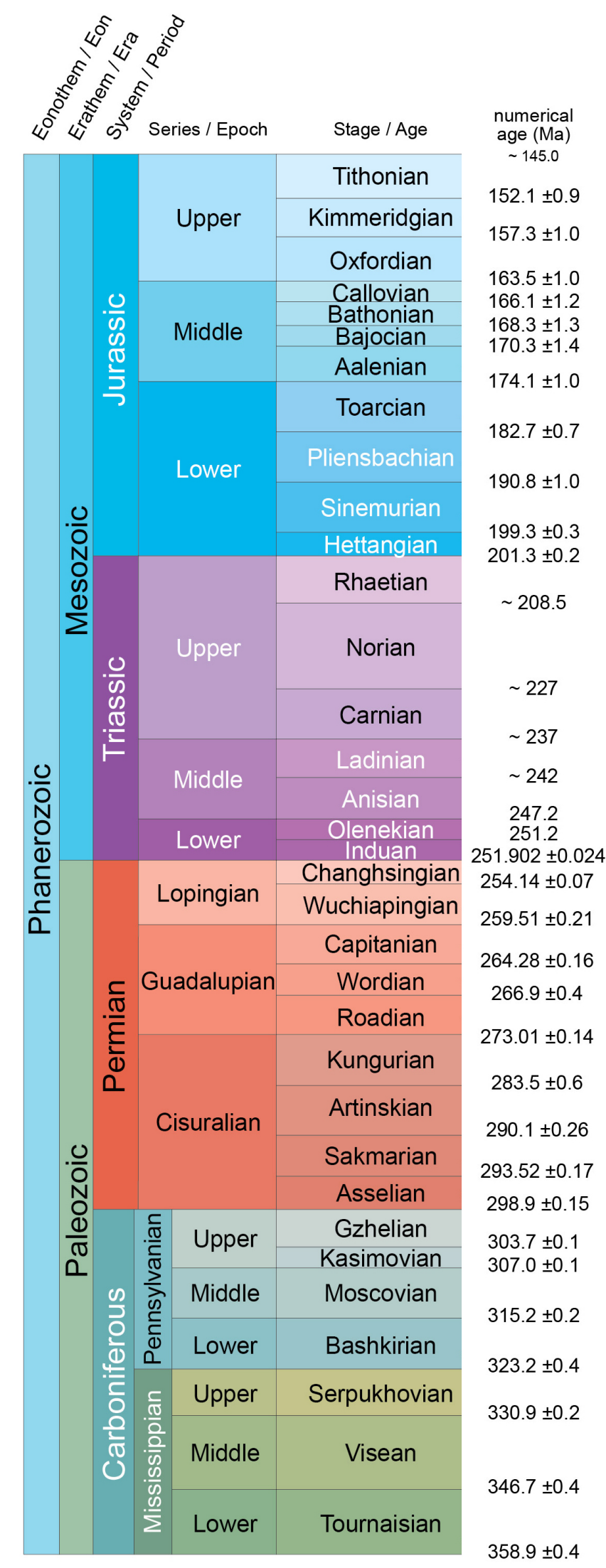

(a) 


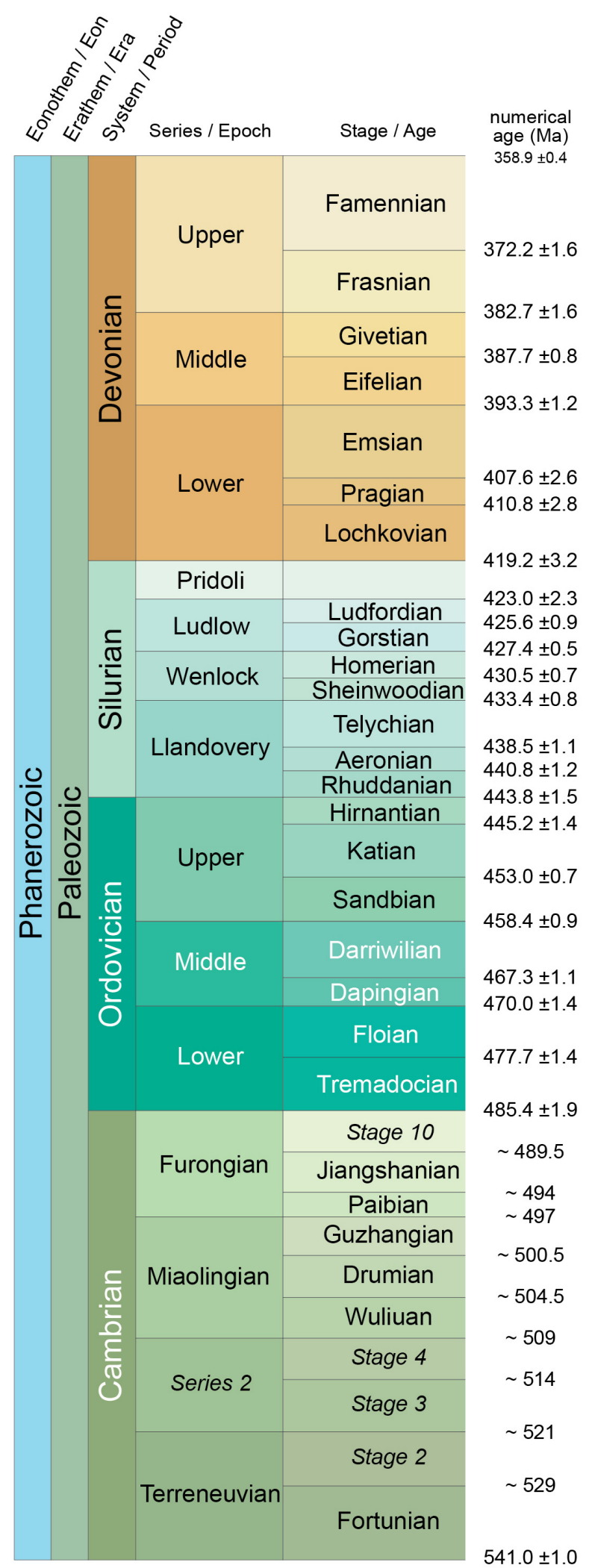

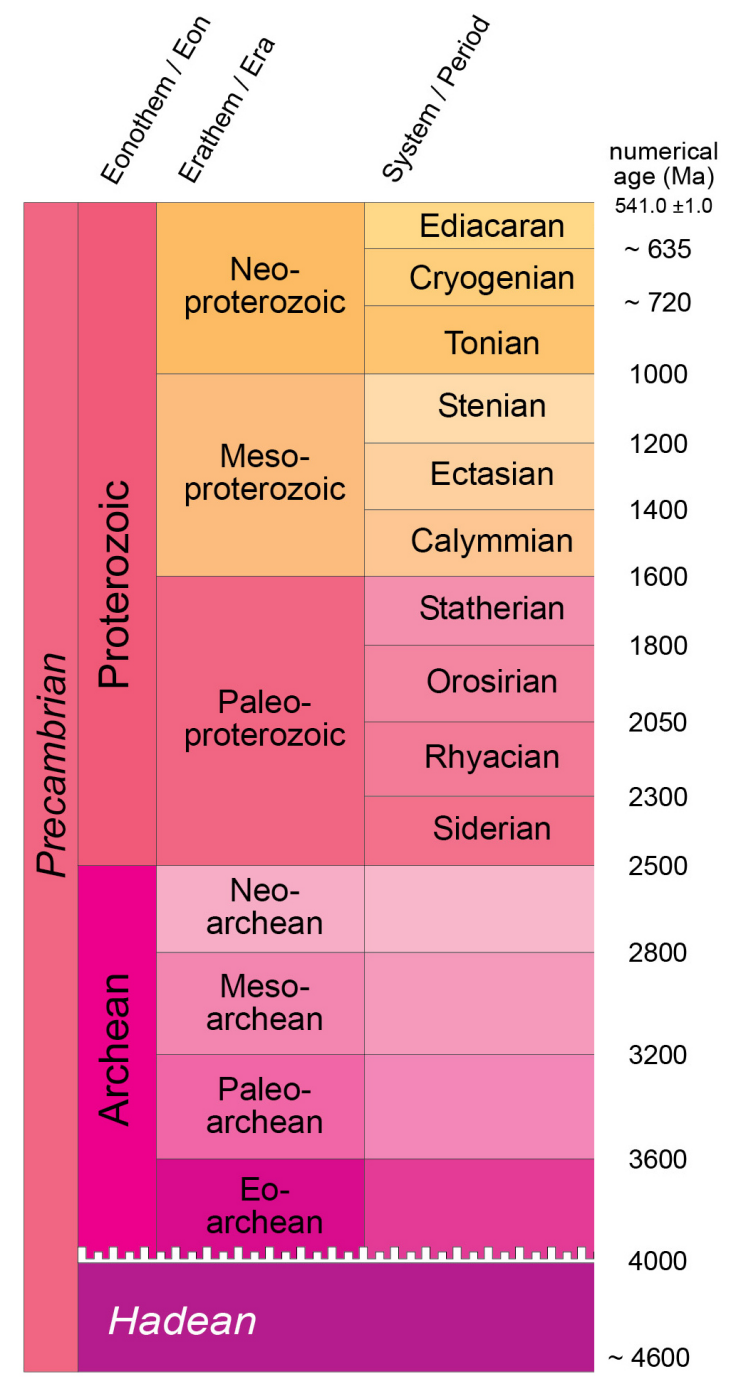

(b)

Figure 2. (a) ICS International Chronostratigraphic Chart: From present to 359 mya (modified from [8]); (b) ICS International Chronostratigraphic Chart: From 359 to 4600 mya (modified from [8]). 


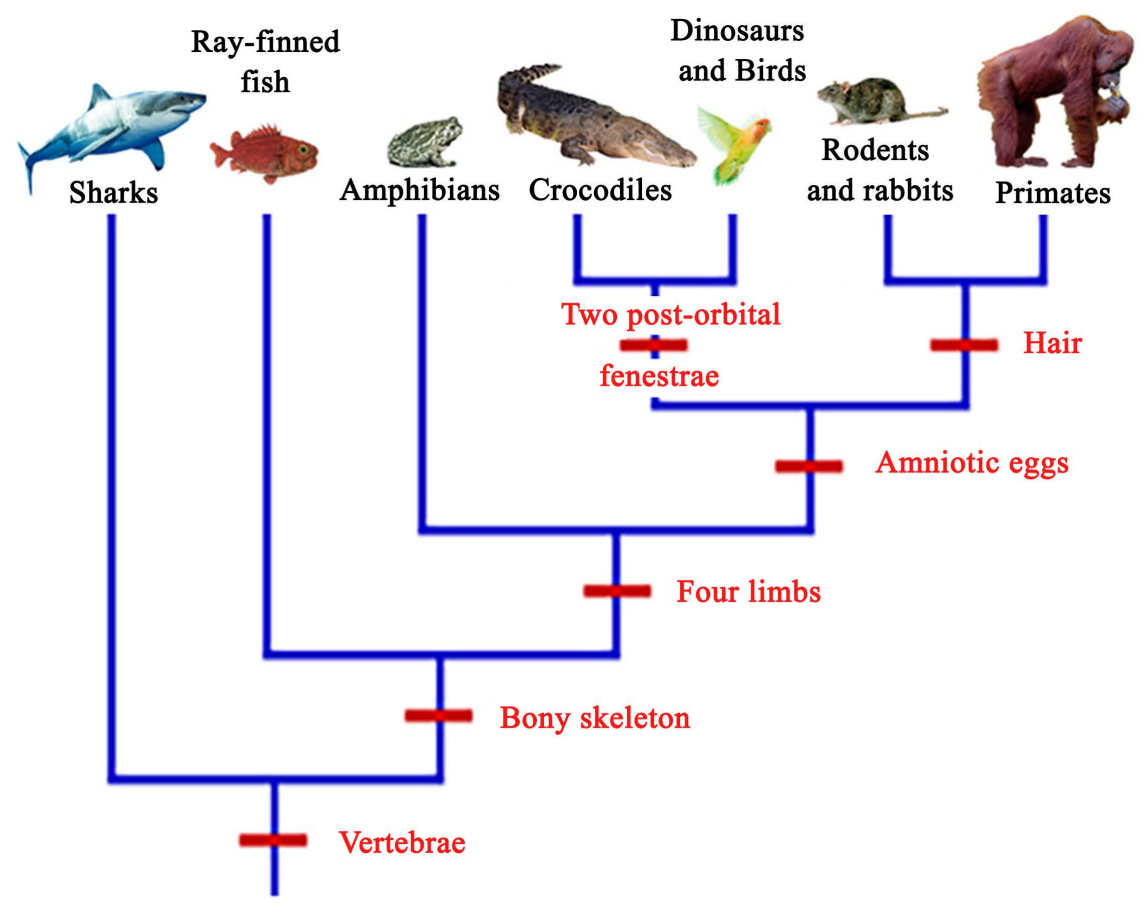

Figure 3. A family tree; in red, evolutional characteristic (see also [10]).

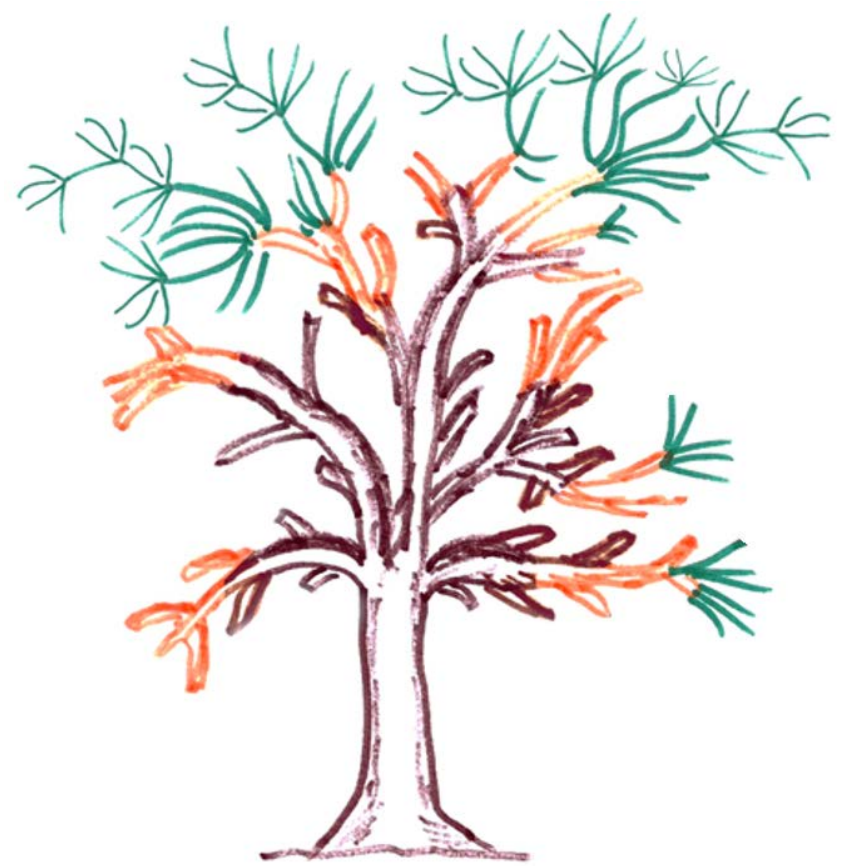

Figure 4. Anatomical diversity in relation to geologic time shows that in the beginning more anatomical forms were created (primary branch structure-brown), with fewer basic anatomies remaining in later times (secondary branch structure-orange) but with more species (green) developing (see also [12]).

develop, including strange wormlike creatures and trilobites. At 470 mya armored fish, with back-bones of less than a foot long, occupy the oceans. Shellfish, nautiluses and corals appear at 420 mya. The next great step is at 400 mya 
when mosses and ferns inhabit the land, followed by centipedes, insects and the first amphibians. At 330 mya giant ferns and club mosses form vast swampy forests, while insects such as dragonflies, with wings $60 \mathrm{~cm}$ across, fly in the air. At 290 mya the age of reptiles begins. At 230 mya reptiles evolve into dinosaurs. Dinosaurs dominate the earth for the next 160 million years. At 215 mya a different group develops into the first mammals that remain small in size and are active mainly at night for the next 150 million years. The first birds take to the air at 150 mya. At 65 mya dinosaurs become extinct and then modern flowering plants appear. At 40 mya mammals evolve into large plant eaters and predators. At 5 mya the ancestors of early humans descend from the apes. These apelike animals walk upright and 130,000 years ago modern humans appear.

A summary of some of the major events that occurred during the earth's past, such as the ones discussed above, is presented in Table 1 [13].

Table 1. A timetable showing major events that occurred in different geological periods (see also [13]).

\begin{tabular}{|c|c|c|c|}
\hline Million years ago & Period & Epoch & Event \\
\hline \multicolumn{4}{|c|}{ Cenozoic era } \\
\hline Present -0.01 & & Holocene & $\begin{array}{l}\text { Rise of human civilization after the } \\
\text { recede of the Pleistocene glaciations }\end{array}$ \\
\hline $0.01-2.58$ & Neogene & Pleistocene & First modern humans appear \\
\hline $2.58-5.3$ & & Pliocene & First cattle and sheep. Whales diversify \\
\hline $5.3-23$ & & Miocene & First apes, mice and many new mammals \\
\hline $23-33.9$ & & Oligocene & First monkeys, deer and rhinoceroses \\
\hline $33.9-56$ & Paleogene & Eocene & First horses, elephants, dogs and cats \\
\hline $56-66$ & & Paleocene & First owls, shrews and hedgehogs \\
\hline \multicolumn{4}{|c|}{ Mesozoic era } \\
\hline $66-145.5$ & Cretaceous & & $\begin{array}{l}\text { First modern mammals. Non-avian } \\
\text { dinosaurs die-out }\end{array}$ \\
\hline $145.5-201.3$ & Jurassic & & $\begin{array}{l}\text { First birds appear, } \\
\text { dinosaurs rule the land }\end{array}$ \\
\hline $201.3-252$ & Triassic & & $\begin{array}{l}\text { First dinosaurs, mammals, } \\
\text { turtles and frogs }\end{array}$ \\
\hline \multicolumn{4}{|c|}{ Paleozoic era } \\
\hline $252-299$ & Permian & & Sail-back synapsids appear on land \\
\hline $299-358.9$ & Carboniferous & & First reptiles and flying insects on land \\
\hline $358.9-419$ & Devonian & & $\begin{array}{l}\text { First vertebrates with four limbs } \\
\text { and distinct digits }\end{array}$ \\
\hline $419-443.8$ & Silurian & & First plants and arachnids on land \\
\hline $443.8-485.4$ & Ordovician & & First nautiloids and jawed vertebrates \\
\hline $485.4-541$ & Cambrian & & All major animal groups appear \\
\hline $541-4600$ & Precambrian & & First single-celled and multi-cellular life \\
\hline
\end{tabular}




\subsection{Paleogeography and Climate}

\section{Continent plates and movement}

The history of biological life follows the geological history of the earth and its environment that shows great changes during the aeons. At the end of each geological era a major event of extinction occurred, which every time obliterated important groups of life. A selection of past maps of the earth is shown in Figure 5 (see also [14]). Current evidence suggests that earth was covered with glaciers twice during the period between about 720 and 630 mya [15]. According to the current interpretation, during the early Devonian (see Figure 5) the continents formed two main land masses, one in the northern hemisphere called Laurasia

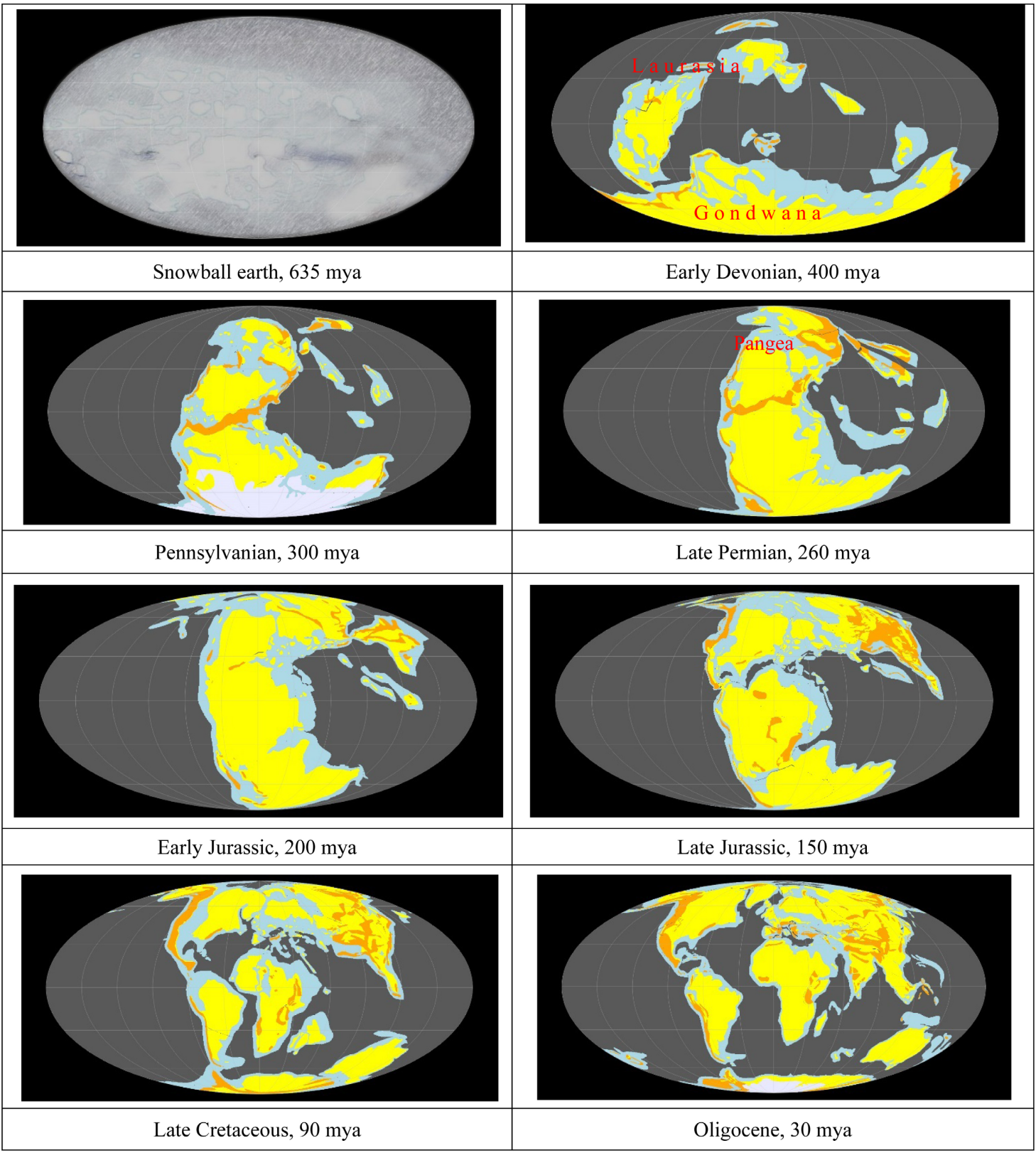

Figure 5. Paleogeographical maps in rectangular format, for various earth ages (see also [17] [18]). 
and one in the southern hemisphere called Gondwana. During the late Carboniferous Gondwana rotated touching Laurasia. During the late Permian Gondwana joined Laurasia to form a super continent called Pangea. During the early Jurassic Gondwana continued to move northward away from the southern pole. During the late Jurassic an equatorial seaway appeared as the northern and southern landmasses separated. During the late Cretaceous the continents continued to separate and began to assume the positions of the present day. During the Oligocene and beyond the movement of landmasses continued to change their position and shape.

According to the above, the continent plates always move slowly on the surface of the earth. In some cases, a large part of the earth may be covered with snow, while in others the ice melts when warm periods prevail. Also, in some periods large parts of the continents may be under water, while in others the same part may rise above the sea. The change of environment is a major factor that affects the life that exists in a specific area.

\section{Mesozoic climate}

The mass extinction, at the end of the Permian, 251 mya, was the most dramatic event with a great impact on life. Life on the seas and on land was nearly destroyed, ecosystems were ruined, and many long-lived lineages vanished. Today, it is widely accepted that this great devastation was caused by large-scale volcanic activity in Siberia that led to major atmospheric changes worldwide and the collapse of the ecosystems. After the extinction event, there were initial rises in various parts of the world, but large drops followed and an amazingly low level of life was sustained through the Early and Middle Triassic [16]. As mentioned above, during the Triassic all continents were already combined to form the single Pangaea supercontinent. The continent was centered, more or less, on the equator and extended to the poles. It was surrounded by the Panthalassa Ocean with Tethys, a deep oceanic gulf to the east of the supercontinent (Figure 6).

In summer, in the circum-Tethyan part of the continent the heating would be maximized because of the concentration of exposed land at low and mid latitudes and the presence of a warm seaway [20]. Furthermore, extreme continentality with hot summers and relatively cold winters and a strong monsoonal circulation would cause widespread seasonal rainfall, concentrated during the summer in the northern hemisphere-a relatively dry equatorial region in the eastern part of Pangaea facing the western Tethys-and a breakdown of the zonal climate pattern [21]. Due to the continuity of the land of Pangea, land animals were able to migrate from the South Pole to the North Pole and life began to re-diversify, recovering from the great extinction. Also, warm-water faunas occupied the Tethys Sea.

At the beginning of the Jurassic another major extinction event, regarded as one of the "big five", occurred. However, a closer examination of the fossil record reveals that many groups-believed to have been significantly influenced by the event-had receded throughout the Late Triassic [22]. By the beginning 


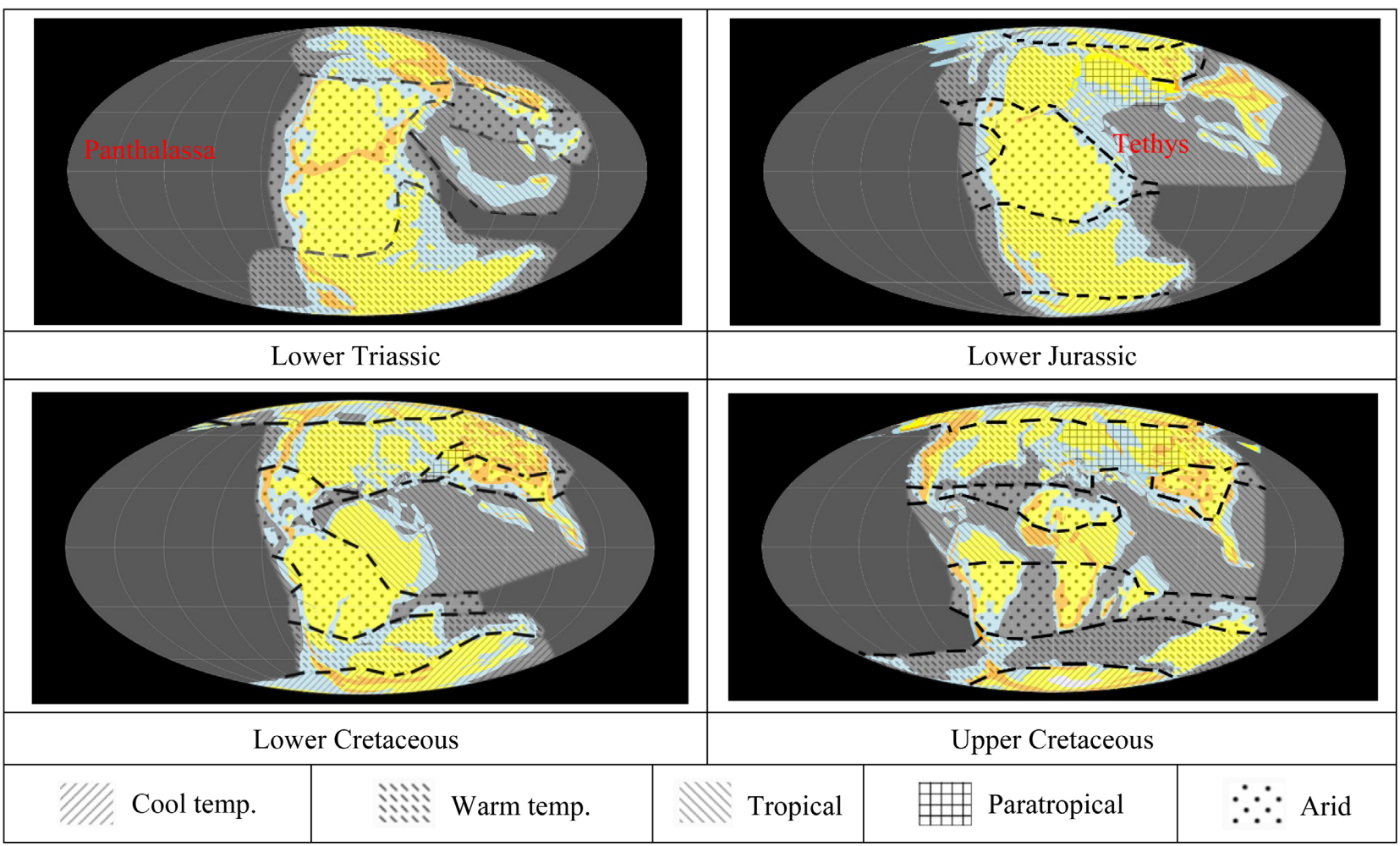

Figure 6. Mesozoic era paleomaps showing the location of continents and their climatic conditions. Tropical climates are associated with coal, bauxite and laterite with warm and wet conditions. Cool temperature is associated with coal and tillites with cool and wet conditions. Arid climate is associated with evaborite and calcrete with warm and dry conditions. Warm temperature is associated with kaolinite with fauna of crocodilus, palms and mangroves. Paratropical climates are associated with high latitude bauxites (see also [17] [18] [19]).

of the Jurassic, Pangaea began to divide into two landmasses, Laurasia in the north and Gondwana in the south. Thus, more coastlines were formed, transforming the continental climate from dry to wet. Throughout the Triassic, the primary dinosaur "competitors", the Crurotarsan archosaurs, were significantly more under stress than dinosaurs and suffered a devastating extinction at the Triassic-Jurassic boundary. In the late stages of the Triassic, dinosaur disparity occurred, giving them the main leap. During the Early Jurassic, dinosaur diversity continued to increase steadily, and measures of diversification and faunal abundance indicate that the Early Jurassic was a major episode in dinosaur evolution [23].

Most chalks were deposited during the Cretaceous period and, because of this, its name was derived from creta that means "chalk" in Latin. Chalk is a type of limestone, fine-grained and soft in composition. The chalk was composed during the Late Cretaceous mainly from the armorlike plates of tiny floating algae. The end of the Cretaceous finds most of the present-day continents separated from each other and is the period where the North and South Atlantic Oceans formed. India drifted into the Indian Ocean, while Australia was still connected to Antarctica. During this period, the high seafloor rates that spread along with the active volcanism probably caused a generally warmer and wetter climate 
than today. Also, the Polar Regions were covered by forests, as the higher temperature did not allow the formation of continental ice sheets as today. Despite the long winter nights, dinosaurs flourished in Antarctica [24].

In the early Cretaceous, flowering plants (angiosperms) appeared and dominated most terrestrial floras until the end of the period. Slightly later than 100 mya many known groups had also appeared [25].

Another of the largest mass extinctions occurred at the end of the Cretaceous (Cretaceous-Tertiary (K-T) extinction), resulting in the extermination of dinosaurs, marine and flying reptiles, as well as many marine invertebrates; about three-quarters of the animal and plant species on earth were exterminated. The most publicized reason for the extinction of dinosaurs is the impact of an asteroid on earth [26]. There exist other theories about the extinction such as volcanic activity, and so on (see discussion in Bakker [27]). Recently a large group of scientists, after examining all the relevant facts, concluded that the extinction that occurred about 65.5 mya is one of the three largest mass extinctions in the last 500 million years. At the time of this extinction event, there was high basalt volcanism in India (Deccan basalt flood), which coincided with a large asteroid impact at Chicxulub, Mexico. The Chicxulub impact was linked to a single global ejecta rich deposit marking the Cretaceous-Paleogene boundary. These co-occurring events, together with other evidence, lead scientists to conclude that the Chicxulub impact activated the mass extinction [28].

In closing this section, it is interesting to see the temperature diversification of the planet at the time of the dinosaurs. Among the many temperature reconstructions during the geological periods, presented in Figure 7 are: 1) A draft version of a recent reconstruction resulting from the cumulative effort that brings together different kinds of observations, models and procedures, with a variety of assumptions [29]; 2) The reconstruction by Scotese [30], where the estimated temperatures were derived from mapped data that can determine the earth's past climate. These data include the distribution of ancient coals, desert deposits, tropical soils, salt deposits, glacial material, as well as the distribution

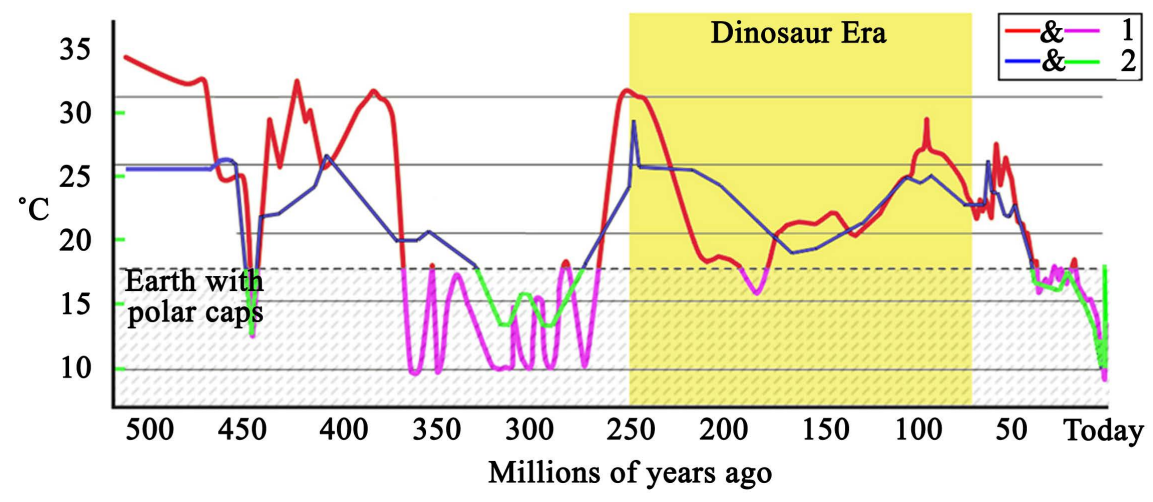

Figure 7. Global temperature variation during the geological periods. During the last 500 million years the earth's climate has alternated between a frigid "Ice House" and a steaming "Hot House", like the world of dinosaurs. Line 1: source [29]; Line 2: source [30]. 
of climate-sensitive plants and animals, such as alligators, palm trees and mangrove swamps. As shown in Figure 7, the Triassic ( 250 - 200 mya) and Cretaceous ( $\sim 145$ - 66 mya) periods had temperatures well above the present average of $17^{\circ} \mathrm{C}$. The intermediate period, Jurassic ( $200-145$ mya), had colder temperatures that were most times much higher than today. During the Mesozoic, there were no continental ice sheets covering the Polar Regions.

\subsection{Animal Classification}

Animals are classified into groups with the smallest unit of classification being the species. Species that share several common characteristics are grouped into genera, genera into families, and so on. The largest group, the animal kingdom, embraces animals of all kinds, including reptiles, fishes, insects and other creatures without backbones. Figure 8 shows the classification of Dicraeosaurus hansemanni (a dinosaur).

Another way of representing relations among organisms is the use of a dia-

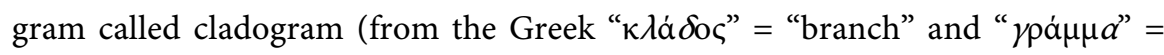

\begin{tabular}{|c|c|c|c|c|c|c|c|}
\hline $\begin{array}{c}\text { Species: } \\
\text { Dicraeosaurusha } \\
\text { nsemanni }\end{array}$ & 115 & & & & & & \\
\hline $\begin{array}{c}\text { Genus: } \\
\text { Dicraeosaurus }\end{array}$ & & $2 \pi$ & & & & & \\
\hline $\begin{array}{c}\text { Family: } \\
\text { Dicraeosauridae }\end{array}$ & & & 29 & & & & \\
\hline $\begin{array}{c}\text { Order: } \\
\text { Saurischia- } \\
\text { 'lizard-hipped' } \\
\text { dinosaurs }\end{array}$ & & & & & & & \\
\hline $\begin{array}{c}\text { Clade: } \\
\text { Dinosauria- } \\
\text { a diverse group } \\
\text { of reptiles; they } \\
\text { first appeared } \\
\text { during the } \\
\text { Triassic period, } \\
\text { between } 243 \text { and } \\
233.23 \text { mya }\end{array}$ & & & & & & & \\
\hline $\begin{array}{l}\text { Phylum: } \\
\text { Chordata- } \\
\text { animals } \\
\text { differentiated } \\
\text { into head, } \\
\text { trunk and tail }\end{array}$ & & & & & & & \\
\hline \multirow[t]{2}{*}{$\begin{array}{l}\text { Kingdom: } \\
\text { Animalia } \\
\text { (all animals) }\end{array}$} & & & & & & & \\
\hline & $\begin{array}{c}\text { Dicraeosaurus } \\
\text { hansemanni } \\
\text { sauropod } \\
\text { dinosaur that } \\
\text { lived in } \\
\text { Tanzania } \\
\text { during the late } \\
\text { Jurassic }\end{array}$ & $\begin{array}{l}\text { Dicraeosaurus sattleri } \\
\text { sauropod dinosaur } \\
\text { that lived in Tanzania } \\
\text { during the late } \\
\text { Jurassic }\end{array}$ & $\begin{array}{c}\text { Suuwassea } \\
\text { sauropod } \\
\text { dinosaur found } \\
\text { in the Upper } \\
\text { Jurassic } \\
\text { Morrison } \\
\text { Formation, } \\
\text { Montana, USA }\end{array}$ & $\begin{array}{l}\text { Brachiosaurus } \\
\text { sauropod } \\
\text { dinosaur that } \\
\text { lived in North } \\
\text { America } \\
\text { during the } \\
\text { Late Jurassic }\end{array}$ & $\begin{array}{l}\text { Allosaurus } \\
\text { carnivorous } \\
\text { theropod } \\
\text { dinosaur that } \\
\text { lived in the } \\
\text { late Jurassic }\end{array}$ & $\begin{array}{l}\text { Dimetrodon } \\
\text { limbatus } \\
\text { (a reptile-like } \\
\text { animal of the } \\
\text { Early Permian } \\
\text { period) }\end{array}$ & $\begin{array}{l}\text { Meganeura } \\
\text { (dragonfly } \\
\text { with } \\
\text { wingspans of } \\
\text { up to } 65 \mathrm{~cm} \text {; } \\
\text { extinct insect, } \\
\text { Carboniferous } \\
\text { period) }\end{array}$ \\
\hline
\end{tabular}

Figure 8. Diagram showing the classification of Dicraeosaurus hansemanni (a dinosaur). 
"writing"). A cladogram consists of lines that branch in different directions ending at a clade; it may be drawn in different ways. Cladograms represent ancestor-descendant relations [31] between groups of different organisms and their evolutionary development, studied in Phylogeny. A cladogram helps visualize the groups of organisms being compared, their relationships and their hypothetical ancestors. Figure 9 shows two examples of such cladograms for the Diplodocoid Sauropods. The rules governing the cladograms are: 1) the direction from the roots to the top is a forward movement in time, with the roots indicating the ancestral lineage and the top the descendants; 2) speciation occurs when a lineage splits to form a number of daughter lineages; 3 ) each lineage has ancestors with unique characteristics and ancestors with characteristics shared by other lineages.

Since complete dinosaur skeletons are rarely found, for the restoration of an extinct animal additional information is required to reproduce any missing parts. This information may come from other part skeletons of the same dinosaur species by scaling or, in the case that the bones are unique, by constructing the cladogram. In this way one can draw information from the nearest known species, by comparison and educated assumption, until sound information is found in the field.

\subsection{Body Symmetry and Anatomical Terminology}

In scientific articles specific terms are used to determine the location of different parts of the body or in relation to other parts. To understand the description, one must become familiar with the different planes of section and specific nomenclature.

Anatomically a body can be described in relation to various planes and directions of view. In general, bodies are radially or bilaterally symmetrical. A body that is symmetrical about a central axis exhibits radial symmetry; such examples

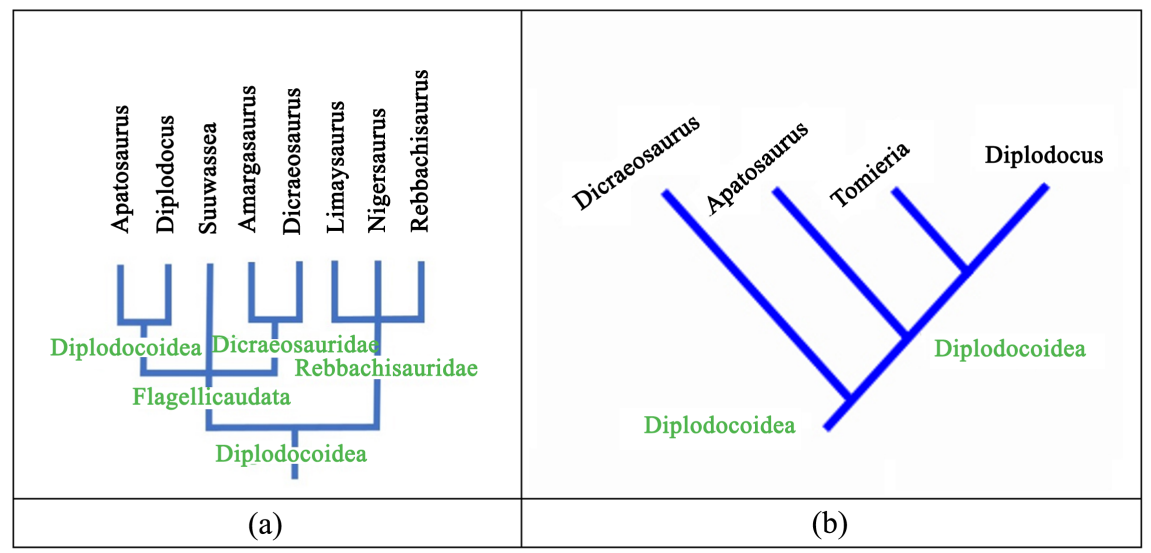

Figure 9. Examples of Diplodocoidea cladograms. (a) Strict consensus Diplodocoidea cladogram based on the phylogenetic hypothesis of Whitlock [32]; (b) Cladogram showing the phylogenetic relationships and higher taxonomy of selected sauropod and outgroup taxa for which endocranial casts are available in the literature, according to [33]. 
are jellyfish, sea urchins and sea anemones (Figure 10(a)). When a central plane divides the body into two mirrored parts, then a bilateral symmetry appears (Figure 10(b)). Bilaterally symmetrical bodies are divided into mirror images through the midsagittal plane.

Figure $10(c)$ shows the terms by which body areas are presented. Generally, anterior means "located or directed toward the head end (cranial)", posterior "toward the tail (caudal)", dorsal "toward the spine or back", and ventral "toward the belly or front".

Medial means "located or directed toward the midline of the body" and lateral "toward the sides". Proximal refers to a body part "closest to the body" and distal to "the farthest". The pectoral region is the region of the chest that connects to the forelimbs (front limbs) and the pelvic region is the region of the hips that connect to the hindlimbs (back limbs).

A frontal plane (or coronal plane) splits a bilateral body into the dorsal (top part) and ventral (lower part) sections; a sagittal plane splits it into a left and right half parts and a transverse plane divides the body into anterior and posterior segments.

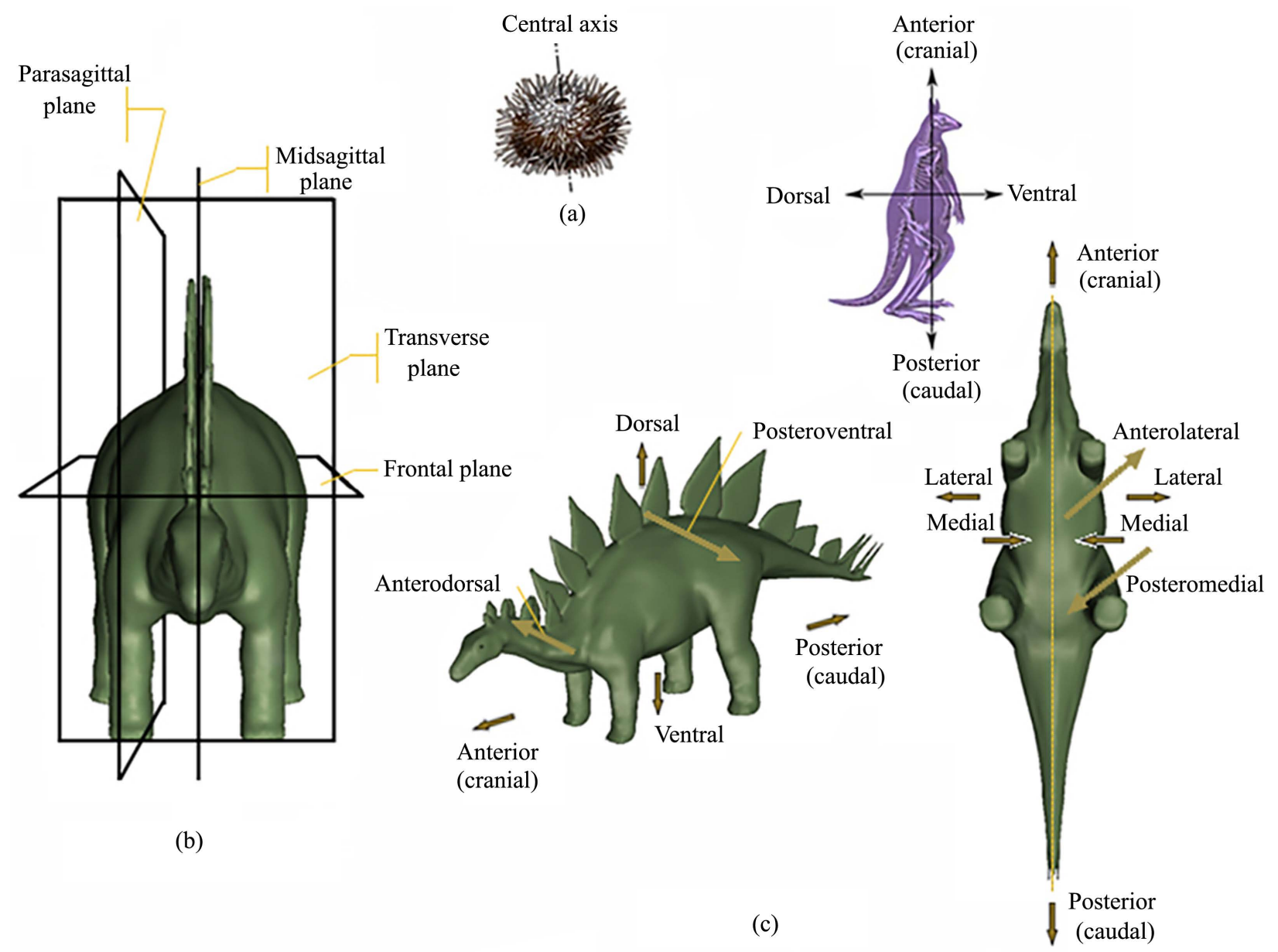

Figure 10. (a) Radial symmetry and (b) bilateral symmetry are the two most common body symmetries, (c) views by which the body regions are presented. 
In medical anatomy, for humans standing on two legs, the term anterior is generally replaced with the term superior and posterior with inferior [34].

The position-related terms could refer to specific parts of the body, but they could also be used as relative terms. More specifically:

1) Anterior: in anatomical terminology refers to structures situated at the front or toward the head end; example: in a dog the eyes are anterior to the ears.

2) Posterior: refers to structures situated or directed toward the rear or tail end of the body; example: in a dog the ears are posterior to the eyes.

3) Caudal: refers to structures of, situated on, or near the tail or the posterior end of the body; the term is similar to posterior.

4) Cranial: refers to structures of or related to the cranium or skull.

5) Superior: refers to structures situated at a higher position compared to something else; example: the neck in humans is superior to the chest.

6) Inferior: refers to structures situated at a lower position compared to something else.

7) Medial: refers to structures close to the center of a body or the median plane; example: the medial side of the left knee is the part close to the right foot; as a relative term, it is the direction from outside toward the middle.

8) Lateral: the opposite term of medial; as a relative term, it is the direction from the middle toward the outside, left or right of the sagittal plane; example: the ischium curves gently laterally in an arc.

9) Proximal: refers to structures situated toward the point of origin or attachment, meaning nearest to the main body.

10) Distal: refers to structures situated away from the main body; also, a given structure can be either proximal or distal in relation to another point of reference; example: the upper arm in humans is proximal and the hand is distal to the body.

11) Dorsal: refers to structures situated at the back (spine) or on the upper side of an organism.

12) Ventral: meaning "belly", refers to the front (for humans or animals walking on two) or lower side of an animal; example: in a fish the pectoral fins are ventral to the dorsal fin.

13) Rostral: when referring to cranium parts it specifies the area of the snout (or muzzle).

14) Longitudinal: refers to structures situated or extending in the direction of the length.

15) Transverse: refers to structures situated in the cross direction.

Some common examples for the above terminology, as found in the literature, are indicated in Figure 11.

Combinations of the above terms are also used, to describe directions that diverse from the main axes. For example, anterolateral indicates a direction toward the head and to the side.

The following terminology is used to identify specific areas of the mouth: 


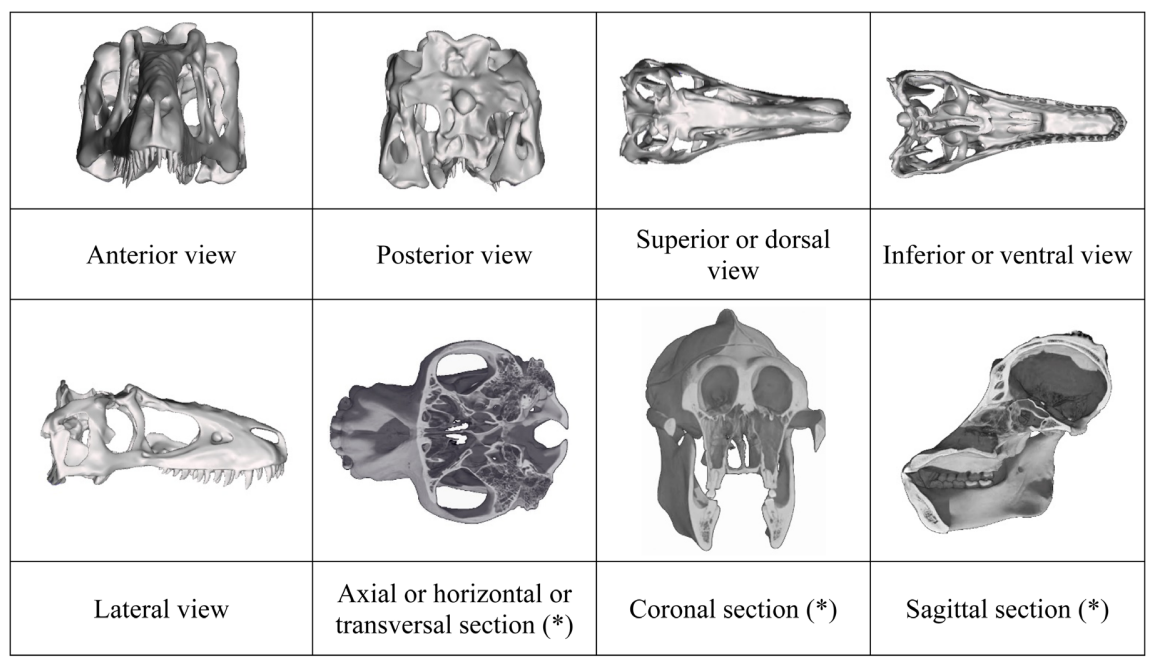

Figure 11. Some common examples of named views and sections, as found in the literature; $\left(^{*}\right)$ modified from [35].

1) Labial: indicates the direction of the lips.

2) Lingual: indicates the direction of the tongue.

3) Buccal: indicates the direction toward the cheeks.

4) Mesial: refers to structures facing or pointing toward the middle of the jaw.

Also, for identifying specific parts of a tooth, it is necessary to utilize named surfaces and directions chosen according to where the part is located. Therefore, the following terminology is generally used:

1) Distal: refers to the surface away from the midline of the face.

2) Facial: refers to the surface that faces the cheeks or lips.

3) Labial: refers to the surface toward the lips.

4) Buccal: refers to the surface toward the cheeks.

5) Incisal: refers to the biting edge of an anterior tooth.

6) Lingual: refers to the surface that faces the tongue.

7) Mesial: refers to the surface that is closest to the midline of the face.

8) Occlusal: refers to the chewing surface of posterior teeth.

9) Proximal: refers to the tooth surfaces that are next to each other.

\subsection{Skeletal Nomenclature}

In order to understand fundamental concepts in the relevant literature, it is necessary to become familiar with the various parts of the skeleton. The science that studies the skeletons, and the bones of which it is made is called Osteology.

The skeleton is divided into an axial and an appendicular part. The axial skeleton comprises the skull, the hyoid apparatus (bones in the neck anchoring the tongue and the throat muscles), the vertebrae, ribs chevrons and sternal plates. The appendicular bones include the limbs and girdles, i.e., shoulders and hips. A general description of the skeleton follows.

\section{Axial skeleton, head and neck}

The head divides into the cranium, which is the rigid upper portion that con- 
nects to the neck and includes the upper jaw and the mandible (the lower jaw). The cranium and jaw are made up of many smaller bones, as indicated in Figure 12. Also, the skull has some natural openings called the fenestra in anatomy, also shown in Figure 12. The posterior part of the skull is articulated to the neck, which is part of the spine. The dinosaur spine (as for all other vertebrates) consists of vertebrae and is divided into neck, trunk (or torso), sacrum and tail (Figure 13). The vertebrae have specific names; those of the neck are called cervical vertebrae, those of the trunk dorsal vertebrae, those of the sacrum sacral vertebrae and those of the tail caudal vertebrae.

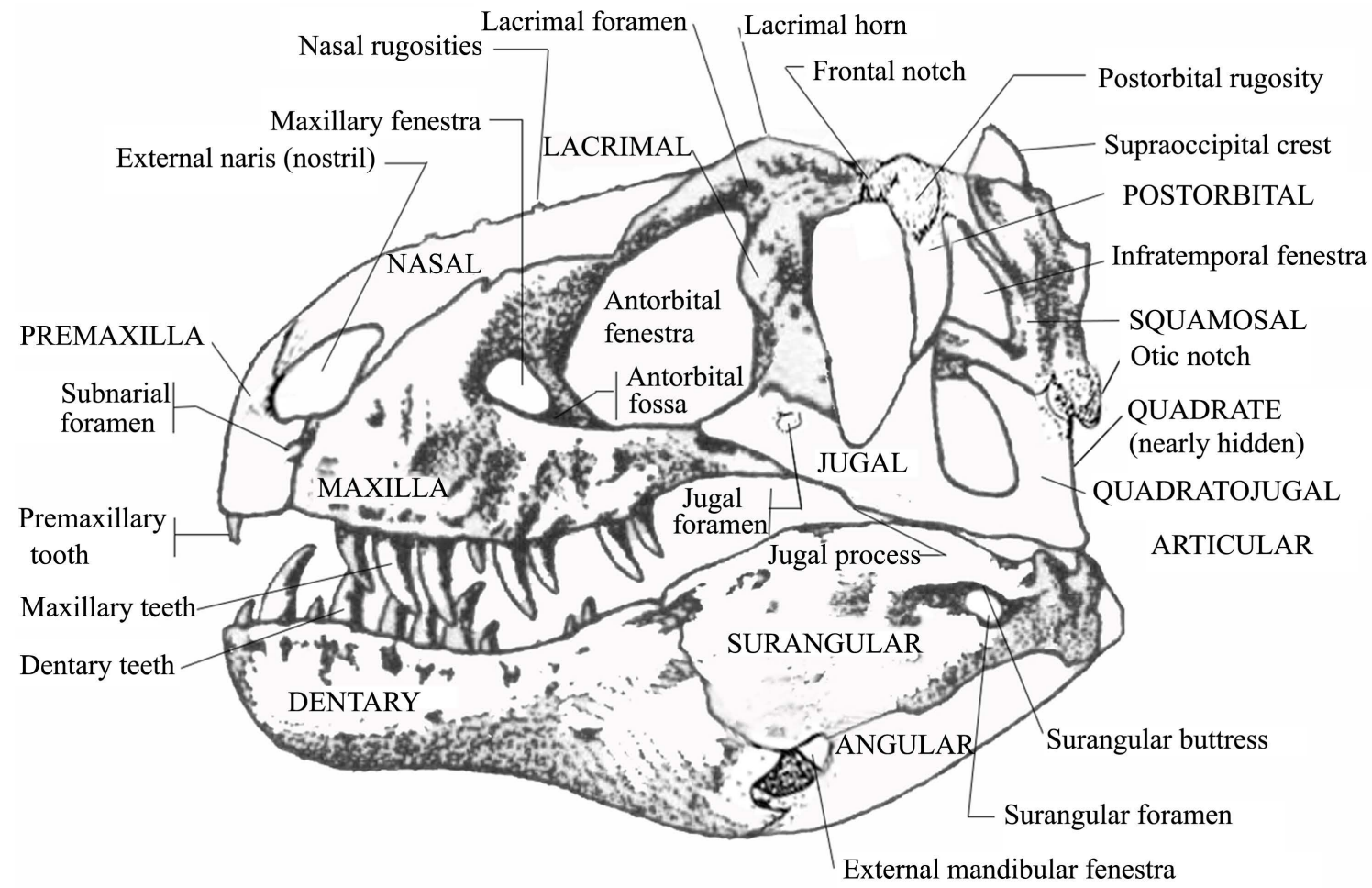

Figure 12. Bone nomenclature of the cranium and the jaw; the natural openings called fenestra are also indicated.

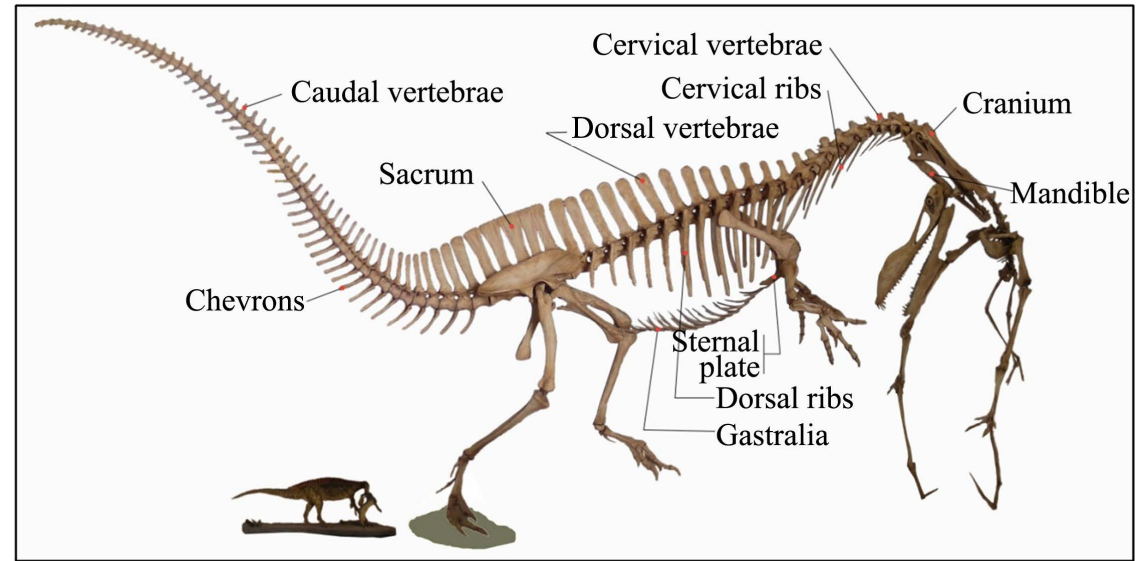

Figure 13. Description of the head and the spine of Sauropods. A skeleton of Irritator Challenger carrying a pterosaur in its mouth [37]. 
The dinosaur cervical vertebrae have backward-pointing ribs underneath, called cervical ribs. The numbering of the cervical vertebrae starts from the head and moves to the back. Each cervical is identified by a number, for instance 1st cervical or C1 (also named "Atlas" from the name of the titan who held the sky on his shoulders in Greek Mythology) holding the head, 2nd cervical (also named "Axis") and so on. Atlas is very distinct, unlike a typical vertebra, shaped like a ring and in sauropods it is very small, smaller than the succeeding vertebrae. Axis (C2) appears like a normal vertebra and has a special articulation at the front, where the Atlas fits. The "cervical" from C3 and backward have a similar shape but increase in size toward the torso. Sauropods generally have between ten and nineteen cervical vertebrae [36]. Below the cervical vertebrae there are cervical ribs.

\section{Axial Skeleton, Body and Tail}

Moving in the direction from head to tail, the cervical vertebrae are followed by a series of dorsal vertebrae. The dorsal vertebrae have dorsal ribs in much the same way as cervical vertebrae have cervical ribs, but the dorsal ribs are vertically oriented and longer than the cervical ribs. The cervical ribs generally (but not always) fuse into their vertebrae, but this is not the case for dorsal ribs that rarely or never fuse. Therefore, this feature could be a way to distinguish a cervical vertebra from a dorsal one. Note that, due to existing exceptions, one should be very careful.

The next group is in the hip area, where a number of vertebrae fuse together. This is called the sacrum and its vertebrae are the sacral vertebrae. The sacral vertebrae also have sacral ribs that usually do not appear in a lateral view.

The tail follows the sacrum and consists of the caudal vertebrae. Below these and between the intervertebral joints are the transversely flattened bones called chevrons or haemopophyses. It is not clear whether the caudal vertebrae have caudal ribs. The first few vertebrae have lateral processes, but in this case, it is still debated whether they are ribs that are fused to the vertebrae, or parapophyses/diapophyses that are fused together. For more details, see the overview in [38].

The rest of the axial bones are the sternal plates located in the front breast area. The exact position and alignment of the sternal plates is not clear, as the latter are rarely found in place and are not firmly attached to axial bones.

\section{Appendicular skeleton, shoulder and forelimb}

The shoulder bones are the scapula and the coracoid. The scapula, also called shoulder-blade, is an elongated bone on the side of the torso, joined to the coracoid at its lower end (Figure 14). These bones together form the shoulder girdle, which connects to the torso by ligaments and muscles.

On the underside, where the scapula and coracoid touch, a hollow is formed, called the glenoid, to which the head of the humerus fits. This is followed by the ulna and the radius, forming the lower limb segment. The lower limb continues with the carpals, or wrist bones, and finally with the manus or hand. The superior bones of the manus are the metacarpals followed by the phalanges. The last 


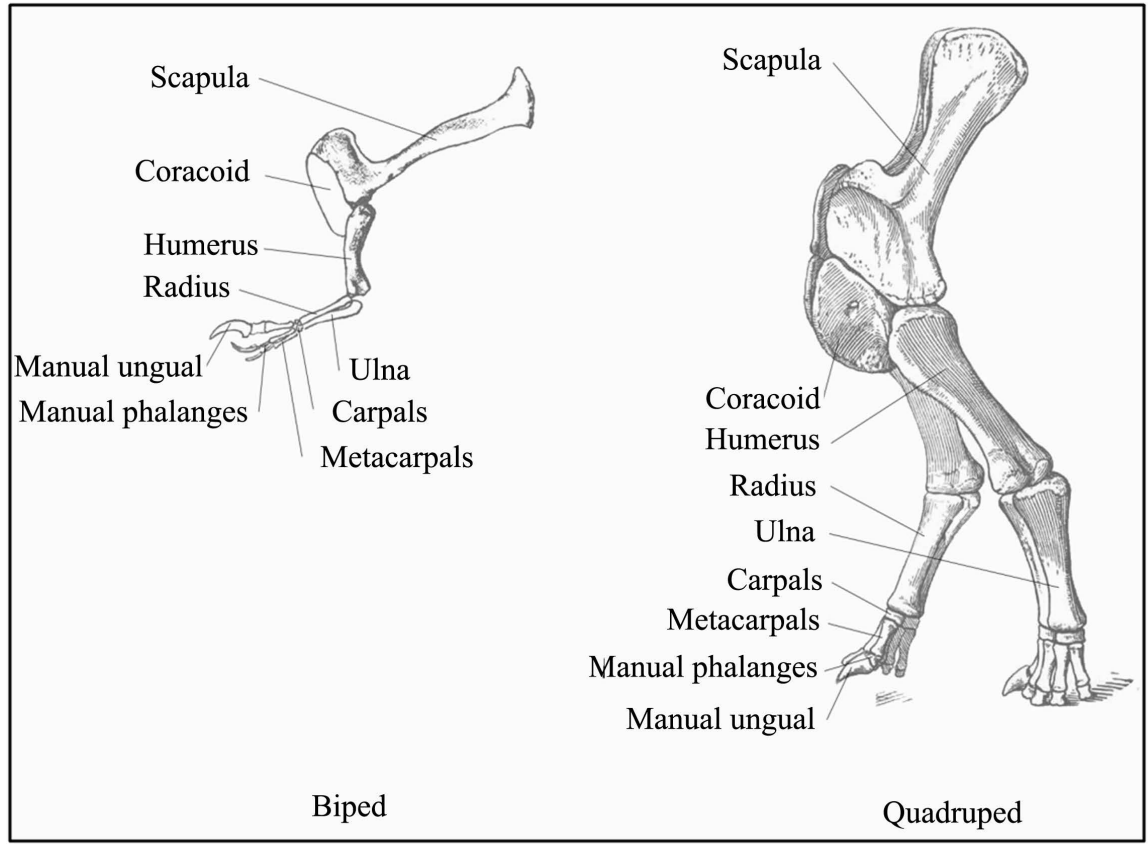

Figure 14. Shoulder and forelimb bones (sketches from [39], Tyrannosaurus and [40], Camarasaurus).

phalanx of a digit can form a claw, called ungual.

\section{Appendicular skeleton, hip and hindlimb}

Three bones on each side, the ilium, the pubis and the ischium form the pelvis, or hip girdle (Figure 15). A circular cavity called the acetabulum, or hip socket, forms at the meeting point of the three bones. The pelvis is fused to the torso through the ilium, which is bonded to the sacrum through the transverse processes of the sacral vertebrae and their sacral ribs. The pubes and ischia do not fuse.

The femur, or thigh bone, has a head that fits the acetabulum. In the knee, the femur joins the tibia and fibula that form the lower-limb bones and lay side by side. The tibia, which carries the main weight, is the thickest of the two and is closest to the midline. Below these two bones are the tarsals, or ankle bones. The tarsal bones are the astragalus (a large, disc-shaped bone below the tibia) and the calcaneum (a smaller globular bone below the fibula) - when present. Finally, the pes, or hind-foot, follows. The upper bones of the pes are the elongate metatarsals followed by the short pedal phalanges and the pedal unguals (as opposed to the manual phalanges and manual unguals of the forefeet).

\section{Bones recovered with difficulty}

In addition to the bones described above, there are some others that are easily decomposed or lost and are usually not recovered. These are shown in Figure 16.

Gastralia, or belly ribs (Figure 13), are dermal ossifications situated in the ventral abdominal wall. They were possibly present in all Sauropods, but they are delicate and usually not preserved. The prosauropod and theropod gastralia 


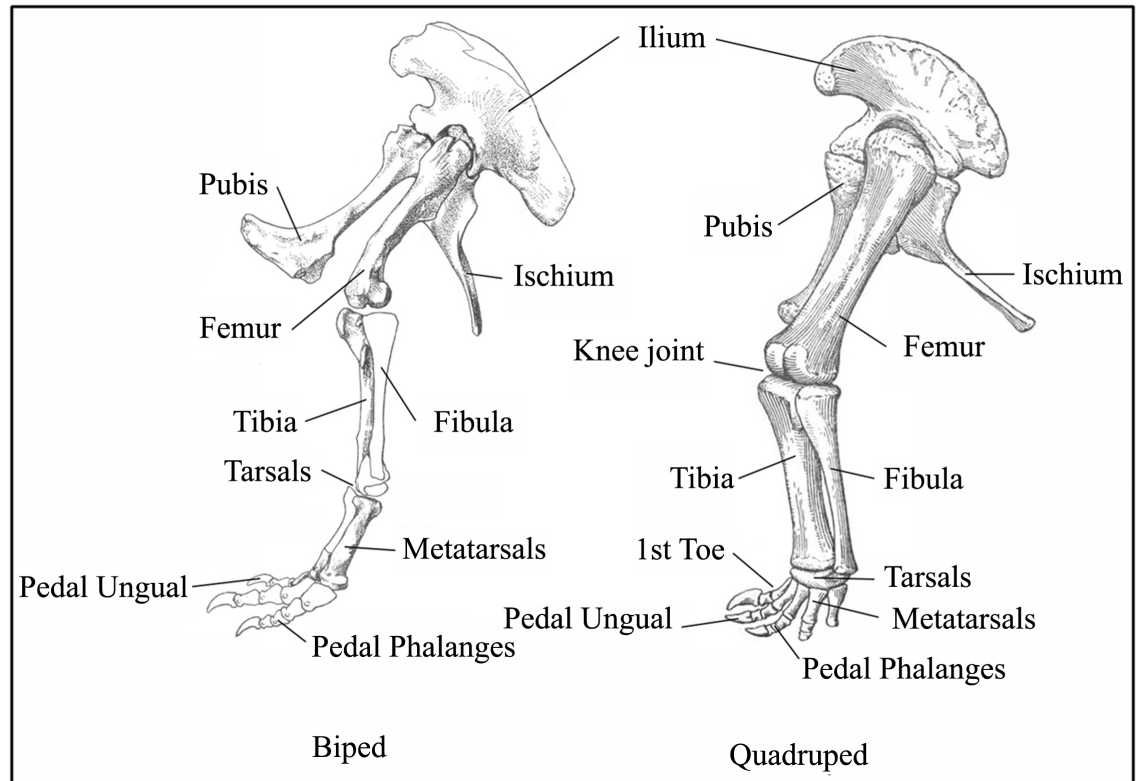

Figure 15. Leg bones of a bipedal and a quadruped dinosaur (sketches from [39], Tyrannosaurus and [40], Ca-marasaurus).

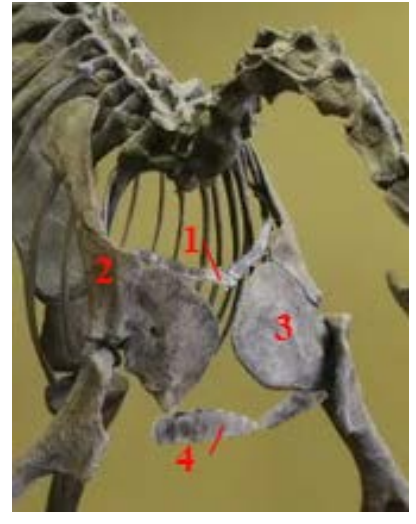

(a)

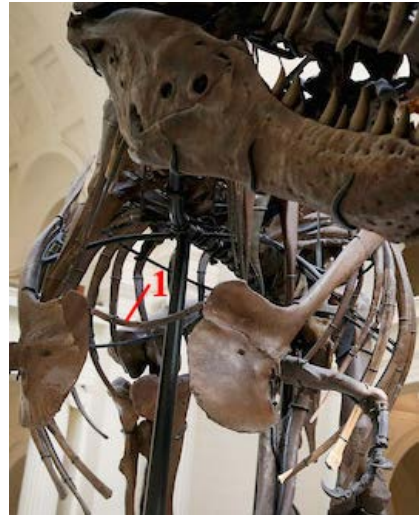

(b)

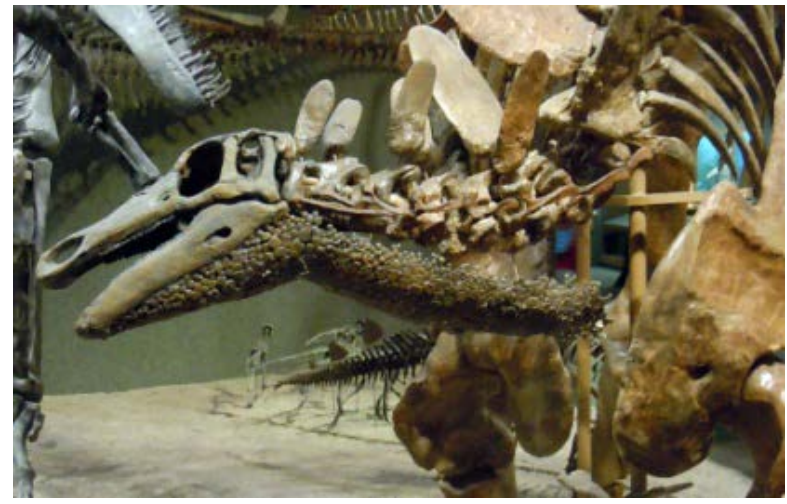

(c)

Figure 16. (a) Reconstructions of the pectoral girdle of Plateosaurus:1-clavicle, 2-scapula, 3-coracoid, 4-sternal plate (see: [42]); (b) "Sue", Field Museum of Natural History, Chicago: 1-furcula; (c) Stegosaur in Denver Museum of Science and Nature, showing plates and bony armor protecting the throat. 
are thin, rod-like bones, between the sternum and the pubis, found in metameric rows on the ventral abdominal wall. Each species has a different number of gastralia rows, ranging from about 8 in smaller species to about 21 in the larger species [41].

Clavicles (collar bones) (Figure 16(a)), found in some dinosaurs, attach the shoulder girdle to the sternum or "breastbone". In theropods (carnivorous dinosaurs), there is a furcula (wishbone) instead of the clavicles (Figure 16(b)). In some of the sauropodomorph dinosaurs, the clavicles do not actually fuse but come into contact with each other with a furcula-like pattern [42].

Finally, some dinosaurs had osteoderms (Figure 16(c)), which may be scales, plates or other structures formed by bony deposits embedded in the skin. Osteoderms are present in various groups of dinosaurs (most notably in ankylosaurs and stegosaurians) and even in Sauropods.

\subsection{Fossil Formation}

There is only a very small chance that a living organism will become a fossil. The majorities of organisms decompose completely or are consumed by other animals. The formation of a fossil depends on the type of remains and the environment that exists. In general, hard parts of animals (such as bones, teeth and shells), as well as plants (such as seeds and woody parts) are covered by sediment (such as sand or mud). The sooner the organism is covered in moist sediment after death, the better the chance to become a fossil, as this way it is protected from scavengers and bacteria. Over millions of years, the sediment is covered at the top with more layers, burying the remains deep in the ground that eventually turn to stone. The remains after burial undergo certain processes that usually include chemical alteration or replacement and compaction.

The calcareous skeletons of marine invertebrates, when dissolved, lead to a fossil that is kept as a mold or cast. In other cases, minerals such as silica, pyrite or others, may gradually replace the original skeleton.

On land, ground water can dissolve the original hard parts of an organism and replace them with mineral substances, in a process called replacement. This chemical action can be slow and can reproduce the microscopic structure of an organism, especially which of bones, shells and wood. The most common replacement minerals are calcite, silica, pyrite and hematite.

In other cases, permineralization may occur. This occurs when groundwater with dissolved minerals penetrates the microscopic pores and voids of material made of bone, shell or wood. The deposited minerals produce stony fossils that still contain parts of the original solid material. More details can be found in [43].

Finally, the sedimentary rock containing the fossil is brought to the surface by earth forces, where erosion by wind and water exposes the material. If the fossil is not found in time, the action of the wind and water can destroy it, leaving no record of the organism. 


\subsection{Posture of Dinosaurs}

Protodinosaurs, the earliest known dinosaurs, originate in Argentina and are about 225 million years old [2]. These dinosaurs are bipedal, meaning walking on two legs, and this could be the original posture of the entire group.

Subsequently, the group diversified into two branches, those of the ornithischia and the saurischia, as named by Seeley [44], making them generally accepted names.

In fact, ornithischia is the order of beaked, herbivorous dinosaurs. The name ornithischia means "bird hip joint" and derives from the Greek "ó $\rho$ u $\theta$ c" = "of bird" and "เoxio $v$ " = "ischium". The evolution of the pelvis is one of the features that most distinguishes these dinosaurs, which eventually became a more bird-like structure regardless of the fact that the birds did not descend from these dinosaurs. The ornithischian pubis bone points posteroventrally to the tail and runs parallel to the ischium. It also has a forward-pointing process to support the abdomen (Figure 17). In contrast, the saurischian pubis is directed anteroventrally, as in the ancestral types of lizards.

The ornithischian pelvis is wider and more stable than that of the saurischians. Over the course of their evolution, ornithischians shifted from bipedal to quadrupedal posture, at least three times, and have demonstrated their ability to adopt both postures at the beginning of their evolutionary history [45].

Some well-known ornithischians are the armored dinosaurs, stegosaurs and ankylosaurs, the "duck-billed" Iguanodon (hadrosaurids) and the horned dinosaurs (ceratopsians).

Saurischia means "lizard hip joint" and derives from the Greek $\sigma a$ i $\rho \alpha$ "lizard" and เoxio $v$ "ischium". All carnivorous dinosaurs (theropods) are saurischians, as are the sauropodomorphs that are one of the two primary lineages of herbivorous dinosaurs.

Some commonly known theropods are the giant carnivorous dinosaurs Tyrannosaurus and Giganotosaurus. The small size Compsognathus and Ornitholestes are also theropods. The body size of theropods is generally assumed to have shrunk over the last 50 million years, eventually evolving into modern-day birds [45]. The well-known sauropodomorphs are the herbivorous Diplodocus, Apatosaurus and Brachiosaurus, which belong to the group of Sauropods.

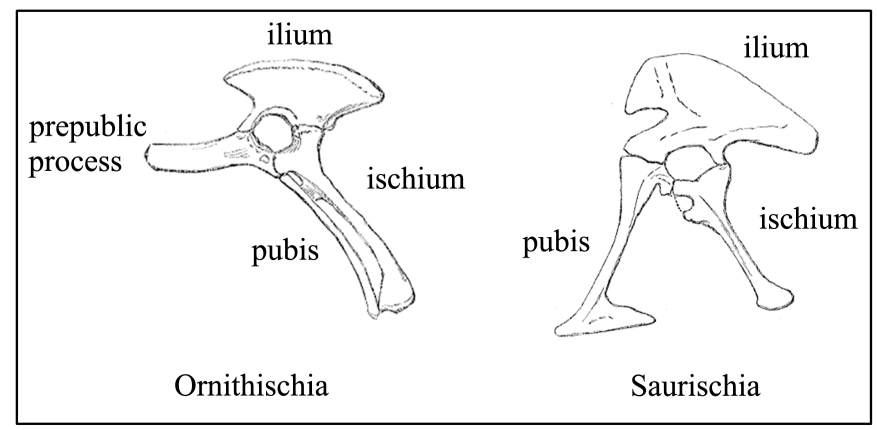

Figure 17. Dinosaur pelvic structure [44]. 
Figure 18 shows the phylogeny of Dinosauria indicating independently-derived quadrupedal, facultatively (contingently) quadrupedal and bipedal lineages. The dinosaurs held their feet directly below their body with their legs operating in the nearly vertical plane. This posture results from the anatomy of the hip socket. The femur shaft ends at a right angle with a cylindrical head that fits into a cylindrical, intra-open hip socket. Figure 19 shows the open hip socket of Dinosauria compared to the hip socket of mammals with a close fit. The ankle was also a simple fore-and-aft hinge joint that also favored a vertical leg posture. The movements permitted by the dinosaur's leg bones are demonstrated in Figure 20.

The dinosaurs were "hind limb dominant" [47] as-whether they walked on two legs or when they were quadrupedal-their weight was mainly borne on the two legs, which were always built stronger than the arms.

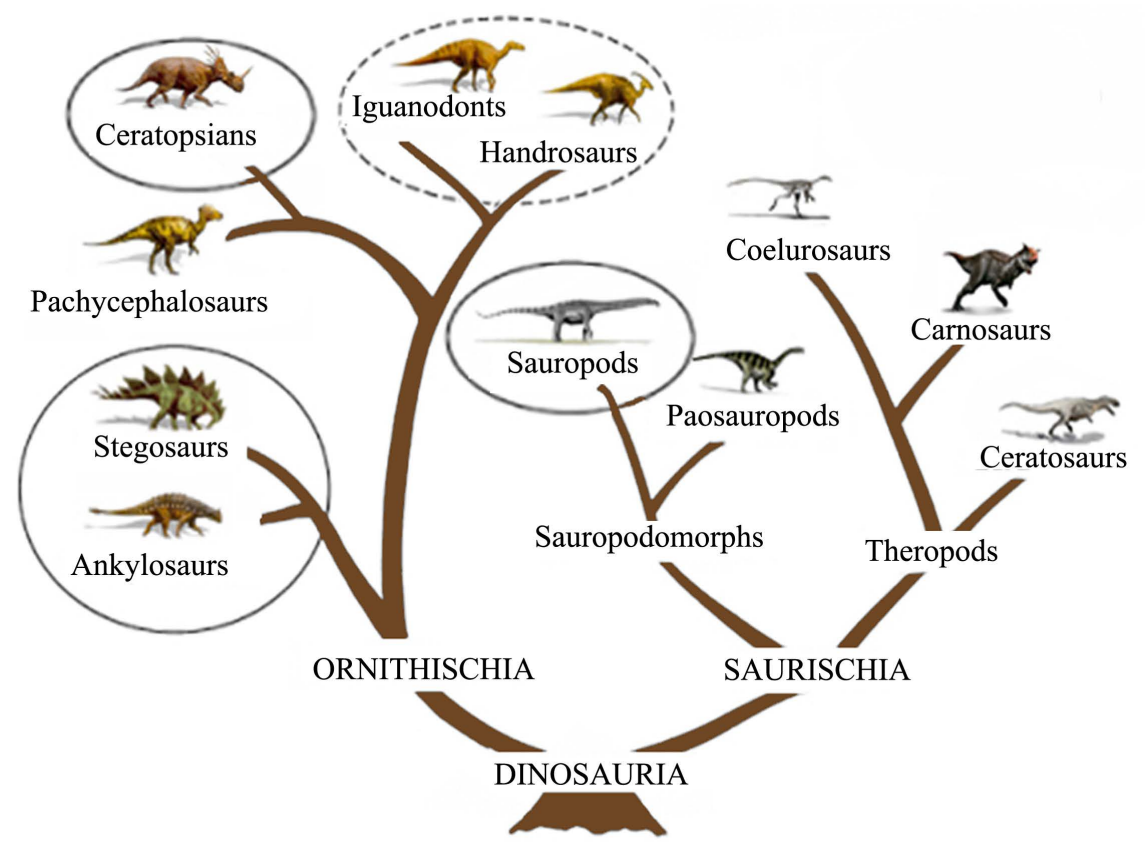

Figure 18. Quadrupedal dinosaurs (in full circles), facultatively quadrupedal (in broken circles) and bipedal dinosaurs (see also [46]).

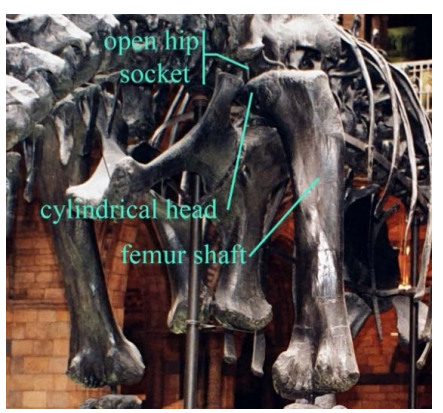

(a)

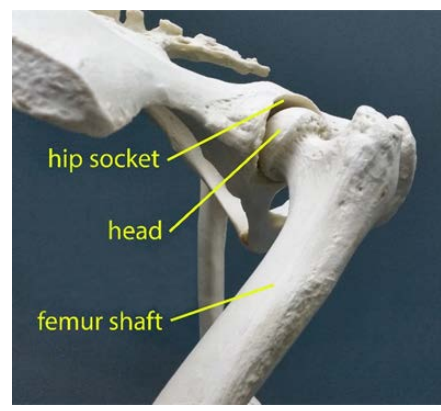

(b)

Figure 19. The anatomy of the dinosaur hip socket compared to mammals. (a) Dinosaur; (b) Mammal. 


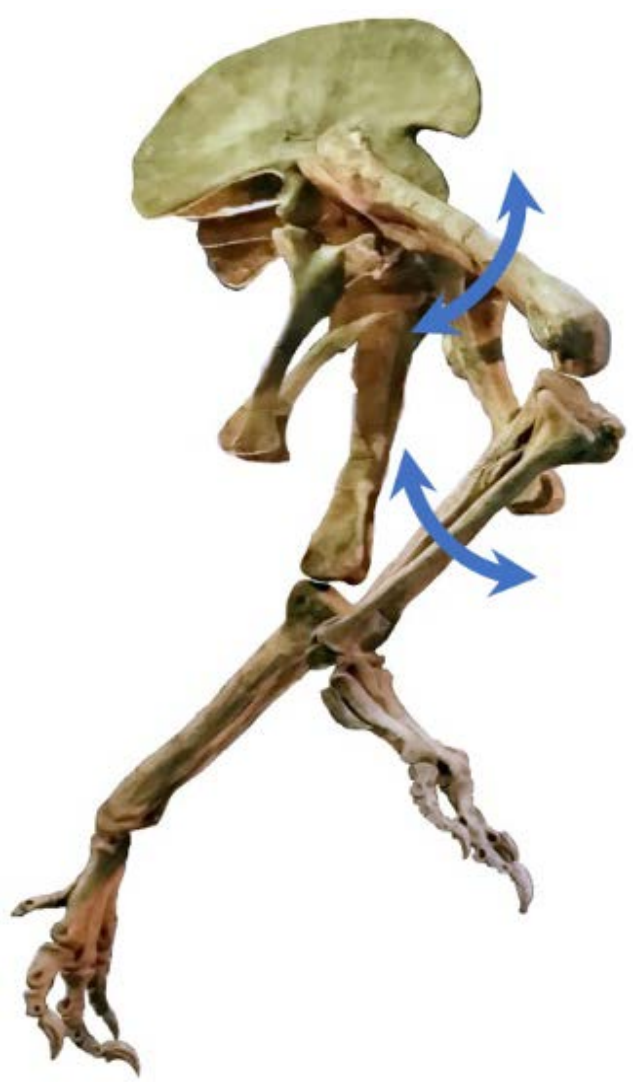

Figure 20. Dinosaur leg bones permit motion forward and backward in only one plane (Suchomimus, Niger, 125 - 112 mya).

\subsection{Dinosaur Tracks}

Another source of information on the dinosaur stance and gait comes from dinosaur tracks. Dinosaur tracks are found in many places, and additionally provide scientific information on foot anatomy, dinosaur behavior, geographical distribution and much more. Tracks are believed to be formed and preserved in two ways. The first is when the dinosaur walked on wet sediment, such as in a mudflat, on a shoreline or even on the bottom of a shallow sea. When the water dried, the tracks hardened, and before being destroyed, they were buried with additional sediment and thus preserved. Another way of forming tracks is when the animal was walking on very soft, muddy soil with its feet compressing the firmer layers below. The surface material then covered the depressions, at the same time covering the prints on the lower layers, forming underprints or undertracks. Figure 21 shows the various types of tracks.

Depending on the specific type and condition of the substrate as well as the foot pressure, there are variations in the appearance of the tracks and the information they convey, as shown in Figure 22.

"Mold" is defined as the impression of a body-part of a dinosaur in the surrounding sediments. The mold is "external" when the external structures are preserved and is "internal" or "steinkern" when the internal features are preserved. 


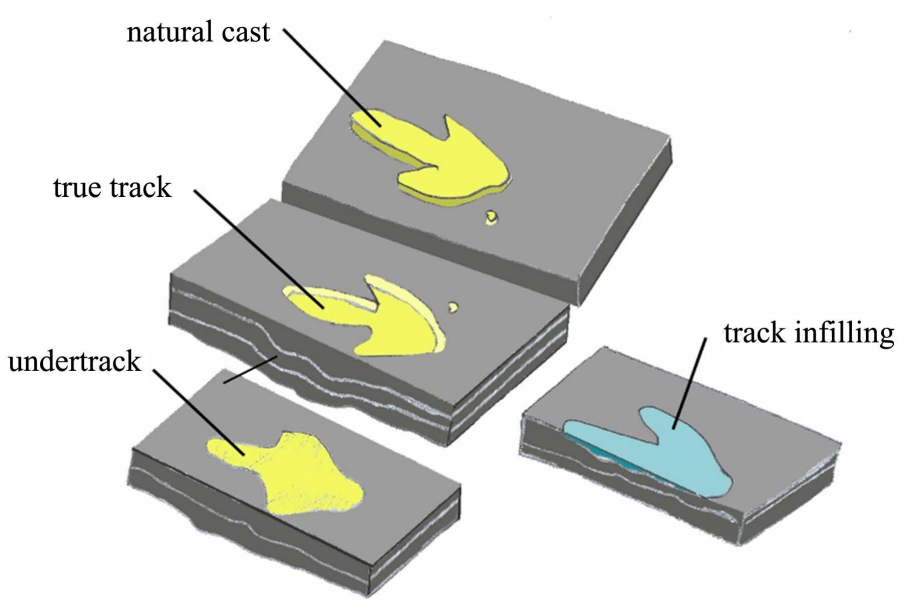

Figure 21. Diagram showing a true track, natural cast, undertrack, and track infilling, as they may be preserved in rock strata (see also [48]).
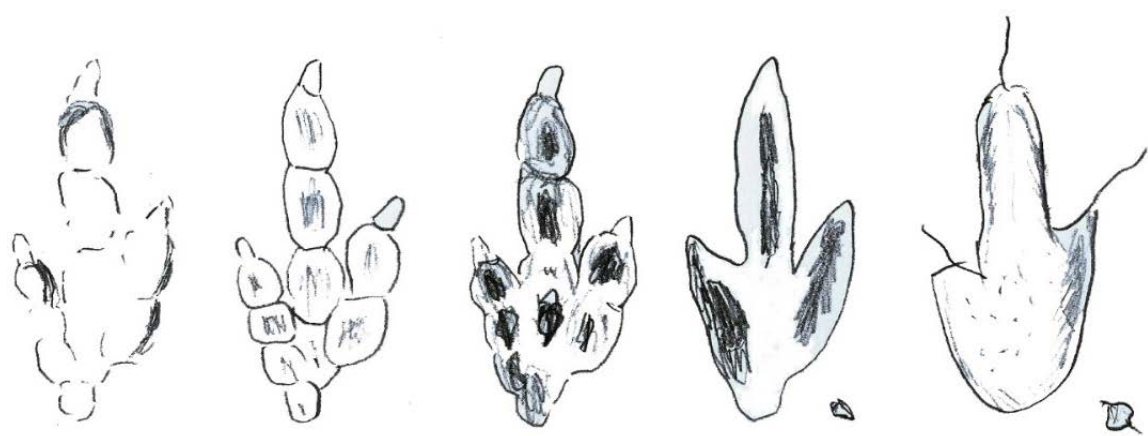

Figure 22. Variations in the appearance of tracks of the same animal based on the type and conditions of the substrate and on foot pressure. Shallow to deep prints from left to right. Far right, mud-collapsed print (see also [49]).

Direct information about the locomotion of dinosaurs derives from their tracks. The trackways show directly whether the animal was walking in a bipedal (two-legged) or quadrupedal (four-legged) manner or altering its step mode in between. They can also show whether a dinosaur was standing, walking or running, or engaged in fighting or hunting.

Gait

Gait is the pattern of movement of the limbs of animals during locomotion. Various gaits are used by most animals, based on their speed and maneuverability, the terrain and energetic efficiency. A predictive method should be used for extinct animals, investigating their trackways and skeletal reconstructions. Extinct animal gaits are classified as walk, trot and run.

Alexander [50] suggests that gait changes are accompanied by changes in relative stride length (Figure 23). Relative stride length is defined as $\lambda / h$, where $\lambda$ is the length of the animal's stride and $h$ is the animal's height at the hip. Animals are believed to walk when the $\lambda / h$ ratio is less than 2.0 , trot when the ratio is greater than 2.0 and gallop or run for ratios above 2.9 [51]. The Length $\lambda$ is measured directly from trackways, while $h$ is estimated from the dimensions of 


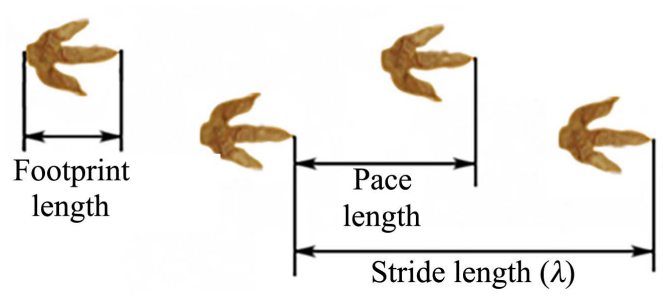

Figure 23. Measurement of footprint, pace and stride length.

the trackmaker's footprints once the species is identified. The parameters measured from footprints and trackways indicate the hip heights. Henderson [52] discusses and compares predictions of hip heights calculated with various formulas.

After determining gait, dinosaur speeds can be estimated from the relationship established between $\lambda, h$, and speed $(v)$.

For walking gait trackways, with a $\lambda / h$ value of less than 2.0 , the speed can be calculated as

$$
v=0.25 g^{0.5} \lambda^{1.67} h^{-1.17}
$$

where $g$ represents the gravitational acceleration [50].

For running gait trackways, with $\lambda / h$ values greater than 2.9 , the following equation can be used for speed [53]:

$$
v=\left\{g h[\lambda /(1.8 h)]^{2.56}\right\}^{1 / 2}
$$

For a trotting gait, when the $\lambda / h$ ratio varies between 2.0 and 2.9, speed can be estimated as the average of the two previously mentioned estimates [51].

Furthermore, the tracks can provide information on how a dinosaur held its tail [54], whether it walked with a narrow or sprawling gait and even the posture of the animal during rest [55]. Tracks may also indicate the social behavior of the dinosaurs and the environment in which they lived. A large number of trails, in the same direction, indicate social herding or migratory behavior [56]. Other tracks have been interpreted as a recording an ancient hunting scene [57]. The tracks also provide additional information on the geographical and chronological distributions of dinosaur groups and can be used as a study tool to provide information on the species population, by tabulation of the proportions of different species [58], the ratio of carnivores to herbivores in a region, and so on.

\section{Reconstruction of foot anatomy from tracks}

The species, the size and shape of a foot and the number of toes in individual prints can be determined by close examination of the tracks. In some cases of clear prints, details of the soft anatomy of the foot can also be revealed, such as the pattern of the pads and the muscles on the feet and the flexibility of the digits.

According to the rules of osteological reconstruction (Heilmann, 1926, Peabody, 1948 and Baird, 1957, in [59], the joints between the bones in the pes are reconstructed in the center of the pads (Figure 24), as found in cursorial birds, 

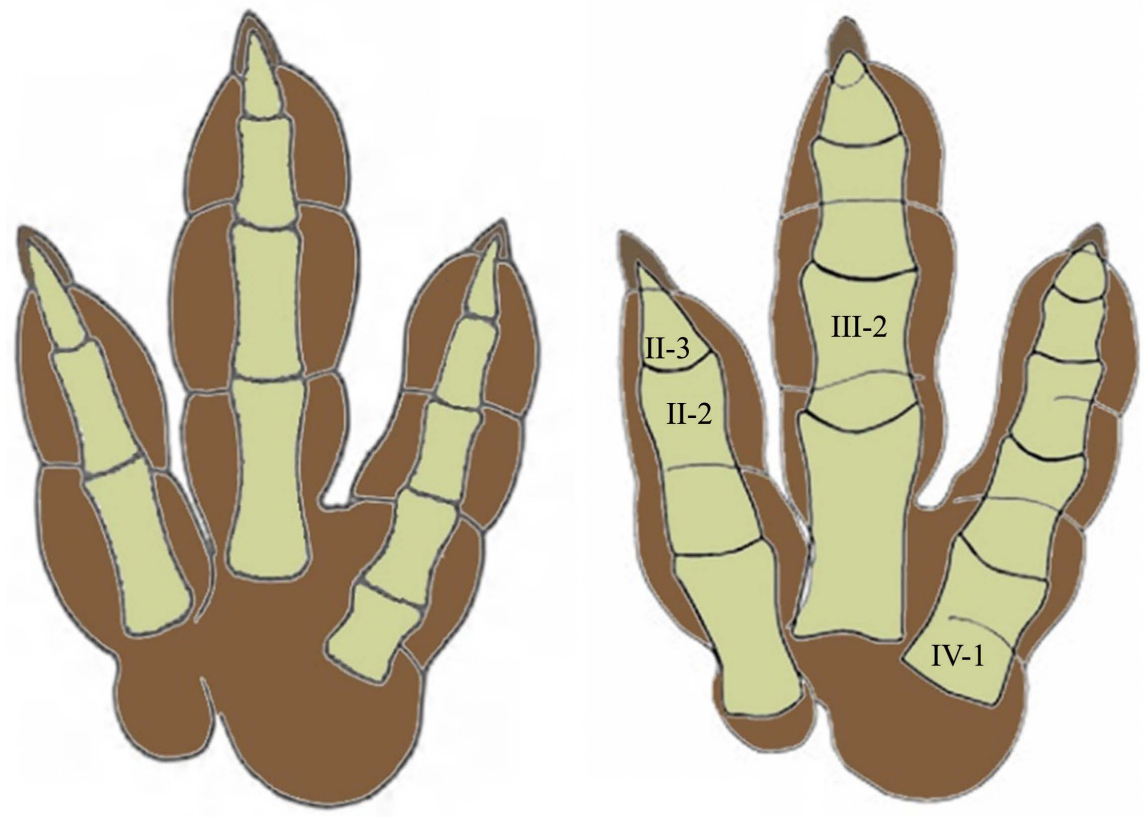

Figure 24. Relationship of digital nodes with foot phalanges. Left: Theropod footprint Eubrontes gigantea, about $37 \mathrm{~cm}$ long. Foot skeleton restored by assuming that the digital nodes are mesarthral in foot-print position; joints between the phalanges coincide with constrictions between the digital nodes of the footprint, adapted from [49]. Right: Theropod foot skeleton restored by assuming that the digital nodes are arthral in position; joints between the phalanges lie in the center of the digital nodes of the footprint, adapted from [60].

and crocodiles and large lizards. Relatively shallow tracks reveal the foot details better, because the knuckles and joints make noticeable deeper and wider impressions on the substrate than the bones in between. It is therefore relatively easy to match the bones on the track. On the other hand, Thulborn [49] states that by using the evidence from existing birds as a guide, the pattern of nodes can vary depending on the species, but also within a species. In general, an interphalangeal joint rarely coincides with the constriction between two digital nodes, and this should be considered in any reconstruction.

\section{Hunting and other traces}

In some cases, the traces indicate that a sauropod is hunted by a meat-eater dinosaur (theropod). Such a case is discussed in [61]. In this case the traces most probably indicate that Paluxysaurus is chased by Acrocanthosaurus, who was following it closely (Figure 25). Other types of traces can be found in [62] [63] [64].

\subsection{Dinosaur Metabolism}

A vital question that has implications for the way dinosaurs are presented in reconstructions is whether the dinosaurs were ectotherms resulting in a slow and reptilian behavior, or endotherms resulting in energetic and active animals like birds and mammals. Ectotherms are organisms that utilize external heat sources to regulate their body temperatures. Endotherms, on the other hand, are organisms 


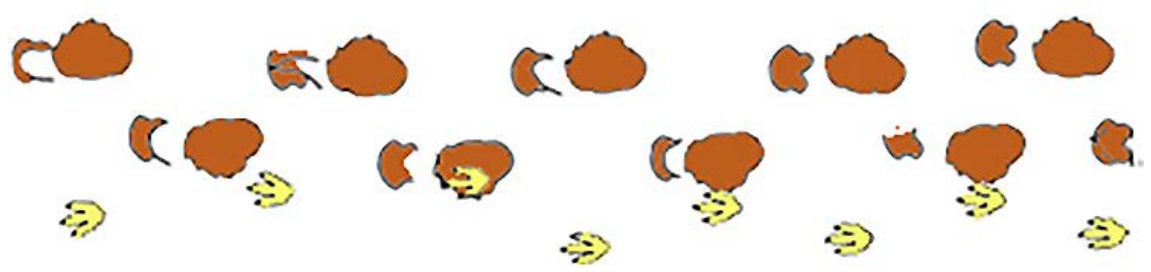

Figure 25. Part sketch of the prints of a theropod-sauropod chase sequence preserved in The American Museum of Natural History and Texas Memorial Museum (modified from [61]).

that regulate their body temperature with their own means. Moreover, some organisms may have a constant body temperature and are called homeotherms, while others may have a fluctuating body temperature and are called poikilotherms.

Ectothermic and endothermic organisms have different biochemical and biophysical methods of generating and obtaining heat, because their metabolism (the sum of the chemical reactions in their cells) is different.

According to Bakker [27], all dinosaurs were automatic endotherms, which means that they had a very high and stable basal metabolism that provided enough heat to maintain a high, constant body temperature, without shivering. In other words, dinosaurs were equivalent to advanced birds and mammals. Evidence that this is true comes from a variety of sources. One such indication comes from the fact that all living endotherms possess four-chambered hearts. Endothermy requires relatively high blood pressures in order to continuously perfuse important organs, such as the brain with a constant supply of oxygenated blood. However, high blood pressures would destroy the alveoli in the lungs [4]. For this reason, mammals and birds have two distinct circulatory systems of the blood, one for the lungs, the pulmonary circuit, and one for the body, the systemic circuit. The four-chambered heart operates in two separate circuits. Fisher et al. [65] examined the chest concretion of an ornithischian dinosaur using computerized tomography (CT) scans. The structures in this area suggested a four-chambered heart and a single systemic aorta, which apparently led them to conclude that intermediate-to-high metabolic rates occurred among dinosaurs. Instead, in a study published by Cleland et al. [66], after re-examining the purported soft tissues of the fossil with high-resolution CT scans and X-rays, the authors found no good evidence that a heart was preserved. As indicated by them, the organ was actually a concretion formed when sand was washed into the body and became cemented in place.

Other indicators in dinosaurs have all produced a somewhat mixed signal, although in some cases they suggest endothermic metabolism. Such indicators are the erect stance argument, the presence of Haversian canals that appears to suggest endothermy, the ratio of biomass in predator and prey ecosystems, the existence of polar-dwelling dinosaurs, the idea that ectotherms would show a greater range of temperature fluctuations from the core to the extremities (measured by the ratios of ${ }^{18} \mathrm{O}:{ }^{16} \mathrm{O}$ ) than endotherms [4]. 
The assessment that birds are dinosaurs suggests that endothermy occurred at least once within Dinosauria [4]. The assumption that dinosaur metabolism may be similar to that of birds, may be derived from soft-tissue vessels and cellular preservation found in dinosaur bones. Schweitzer et al. [67] published a study describing such material found in Tyrannosaurus rex (Figure 26). The preserved material discloses transparent, flexible, hollow blood vessels containing small round micro-structures that can come out of the vessels in solution. Seen under a scanning electron microscope, the features on the external surface of dinosaur vessels are very similar to similarly prepared vessels of the present-day ostrich, suggesting a common origin. Moreover, Bertazzo et al. [68], while examining cretaceous dinosaur bones, observed structures consistent with putative erythrocyte remains that exhibit mass spectra similar to emu whole blood. Further findings will prove or disprove such a proposition.

It was almost unbelievable when soft tissue material was first reported, because it was not considered possible that such material from the Cretaceous Period (66 - 145 mya) could survive. The significance of such reports has therefore been questioned. Nowadays, a number of such reports exist (for instance [69] [70] [71]). Also, the discovery and sequencing of ancient proteins now seems possible and is observed in multiple fossil specimens [69].

In an unexpected turn, an even more "provocative" report by Lee et al. [73] presented the existence of indisputable ancient collagen and protein remains found in a 195 million-year-old fossil. This was confirmed for the early Jurassic sauropodomorph dinosaur Lufengosaurus by an in-situ SR-FTIR microspectroscopical examination. This shows that organic remains can be preserved for more than 100 million years, and indicates the importance of using in-situ methods for this type of investigations.

Notwithstanding the above finds, there is still disbelief about the preservation and endogeneity of ancient soft tissues and composite molecules. This is due to the theoretical temporal limits of molecular preservation, which are considered to be less than 1 mya for proteins and about 100,000 years for DNA, based on
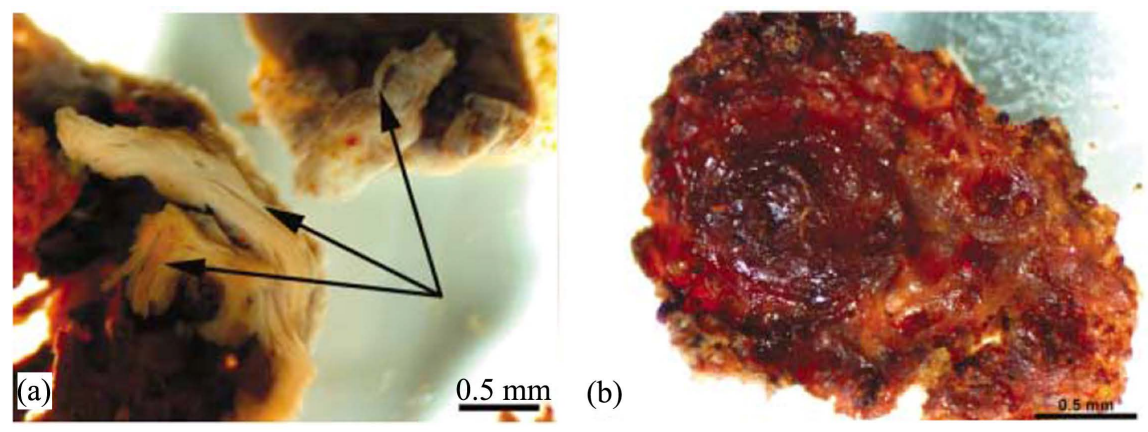

Figure 26. Demineralized fragments of endosteally derived tissues lining the marrow cavity of the T-rex femur: (a) The demineralized fragment is flexible and resilient with regions showing fibrous character (arrows); (b) Demineralized bone after air drying (scale bars $=0.5 \mathrm{~mm}$ ) (from [72], reprinted with permission from AAAS, https://www.science.org/doi/10.1126/science.1108397). 
the degradation proxies of heat and/or $\mathrm{pH}$ models of breakdown kinetics ([74] and references therein). To test the validity of the temporal limits, Allentoft et al. [75] investigated mitochondrial DNA (mtDNA) from 158 radiocarbon-dated bones of the extinct New Zealand moa. The authors confirmed that sequenceable bone DNA fragments are still present, more than 1 million year after deposition in deep-frozen environments, but consider it highly unlikely that an authentic mtDNA fragment of a bone aged 80 - 85 mya could be traced. Unless a preservation mechanism is proven to exist, no soft tissue material will be accepted as original.

\subsection{Dinosaur Reproduction}

The dinosaurs reproduced with eggs and not live young (juveniles), as evidenced by fossil eggs, nests and findings of embryonic skeletons and soft tissue. The eggs of various groups of dinosaurs have been documented on almost all continents. From what is known, dinosaurs produced hard-shelled eggs, like those of birds, rather than eggs with softer shells of reptiles and crocodilians [47].

The first verifiable nests were described and interpreted in the 1920s [76] in the Gobi Desert of Mongolia, when Protoceratops skeletons, associated with fossilized eggs in circular nests, were discovered. In another case, the skeleton of a carnivorous dinosaur was found on top of an egg clutch, indicating that it attacked the nest for food, hence the name Oviraptor or egg thief [77]. It was later discovered that the eggs were in fact those of Oviraptor itself protecting his own nest [78].

Jack Horner, along with Bob Makela, discovered the first dinosaur nests in North America belonging to the Late Cretaceous ornithopod Maiasaura (meaning "good mother reptile"). Their work and further studies changed the image of dinosaurs from solitary and ruthless creatures to social, caring animals [76], and provided the main evidence of parental care among dinosaurs [79].

In the 1990s, the largest known dinosaur nesting site was found at Auca Mahuevo, Argentina. It was documented that sauropods gathered in large numbers to lay their eggs on the soft substrate of a floodplain. Occasional heavy rains flooded the nesting colony, burying and preserving the eggs and embryos of these dinosaurs [80].

\section{Dinosaur nesting behavior}

The dinosaurs probably used different methods for nest building, incubation and parental care, in a similar way that different types of birds do today. Paleontologists are able to attribute eggs to specific dinosaur groups, by using CT scans to inspect the embryos inside eggs or examine juveniles in nests. Dinosaur eggs vary greatly in shape, surface ornamentation and pore distributions. Typically, theropods laid ellipsoidal (oval) eggs with a smooth surface or weak markings or ridges in the direction of the long axis of the egg. The eggs of herbivorous-sauropod and ornithopod-dinosaurs had spherical shape (Figure 27), with a surface with dense and compacted bulges or a network of bulges and irregular 


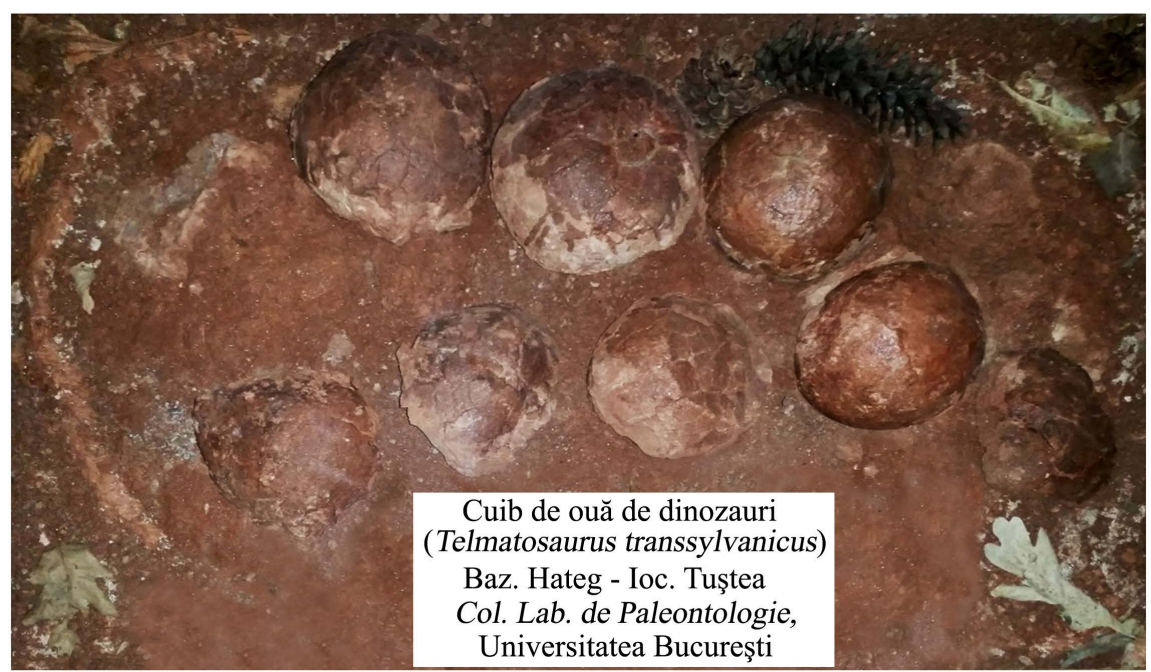

Figure 27. Egg nest of Telmatosaurus transsylvanicus, a Late Cretaceous dinosaur. Telmatosaurus was a relatively small hadrosaur, about five meters long. University of Bucharest, Romania.

ridges [81]. Dinosaur eggshells were made of calcite that had tiny pores allowing the developing embryo to "breathe".

Evidence from the Auca Mahuevo site shows that the sousopods laid 15 - 34 eggs in a simple depression in the sand. In that place hundreds of animals nested together, placing their nests close together, probably relying on the heat of the sun to incubate the eggs. Based on observations in the egg quarry, it has been ruled out that the parents directly took care for their own nest, although sauropods could jointly guard the whole nesting colony by patrolling the periphery of the nesting area to prevent potential predators [80].

The hadrosaur Maiasaura nested in large colonies of well-spaced nests, with adequate space between them, allowing parents to tend their babies. Maiasaura laid a minimum of 11 eggs [76] and placed them in a circular, elevated nest. Maiasaura is believed to have covered the incubating eggs with vegetation that kept the eggs warm as it rotted. Maiasaura babies were left in the nest and their parents took care of them by feeding and protecting them.

Theropods such as Troodon [82] and Oviraptor (Figure 28) laid 16 - 24 eggs arranged in a spiral pattern into a dish-shaped nest. Fossils of adult theropods' skeletons were found above egg clutches, which showed that they were sitting above their nests during the incubation. Thus, they used the warmth of their feathery bodies to incubate their eggs. The parents stayed close to the nest for both prolonged egg-laying and brooding.

Dinosaur eggs came in various sizes. Those of the small dinosaurs were between the size of the eggs of reptiles and birds. It is interesting to note that no known dinosaur egg matches the size of the gigantic, 12-kg eggs laid by the flightless elephant bird Aepyornis, which weighs about $400 \mathrm{~kg}$. The eggs of the giant sauropods, for instance, weighed less than $1 \mathrm{~kg}$. The largest dinosaur eggs ever discovered weigh $5 \mathrm{~kg}$, and probably belonged to 1-ton-plus oviraptors [47]. 


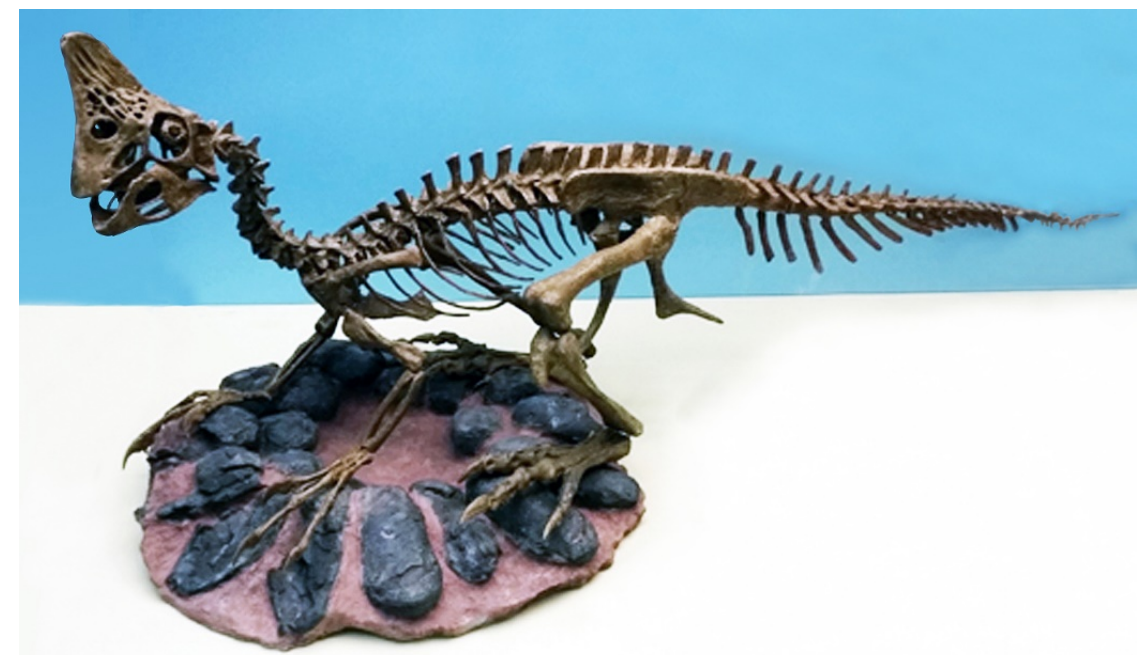

Figure 28. Oviraptor sitting on a nest of fossilized eggs. Schengen Frankfurt Museum.

There are many cases in the world of nests found with fossilized dinosaur eggs and embryos, allowing detailed studies of the nesting behavior and juvenile body size. One such case is shown in Figure 29, which shows dinosaur eggs with embryos, estimated to be at least 65 million years old [83].

There are various criteria by which dinosaur eggs are characterized. Criteria for the species include egg size (length, width and volume), eggshell thickness (best determined by an egg clutch because all the eggs are of the same species), pore pattern (minute oval to circular openings on the surface of the shell), and details of the ornamentation. The genus of the eggs is distinguished by the egg size, the morphotype (type of morph or form), the type of pore canals (tiny canals that connect the inside with the outside, through which the embryo breaths) of the egg, and the surface ornamentation. And finally, the characters of the egg family include morphotype, pore canal type and surface ornamentation [84].

The smallest dinosaur eggs were only a few centimeters long. Large sauropod eggs could be $30 \mathrm{~cm}$ long and $25 \mathrm{~cm}$ wide. The largest dinosaur eggs belong to a giant oviraptor from China and are more than $60 \mathrm{~cm}$ long [85].

Based on typical extant avian incubation periods, dinosaur eggs were thought to hatch very rapidly, in about 11 days for small eggs to 85 days for large ones. Erickson et al. [86] also report the discovery of incremental lines in embryonic dinosaur teeth that provide direct empirical estimates of their incubation periods. For non-avian ornithischian taxa, from small to large, the authors found that the dinosaurian incubation periods were unexpectedly slow (83 days for small and 171 days for large) like those of outgroup reptiles. Their analyses show considerably slower development, suggesting that most, if not all, toothed dinosaurs and basal toothed birds had slow reptilian-grade incubation.

\subsection{Dinosaur Age Estimation}

Estimating the age of the various individual dinosaurs, when they died, is very useful in estimating lifespan (longevity) and growth rates. To accomplish the 


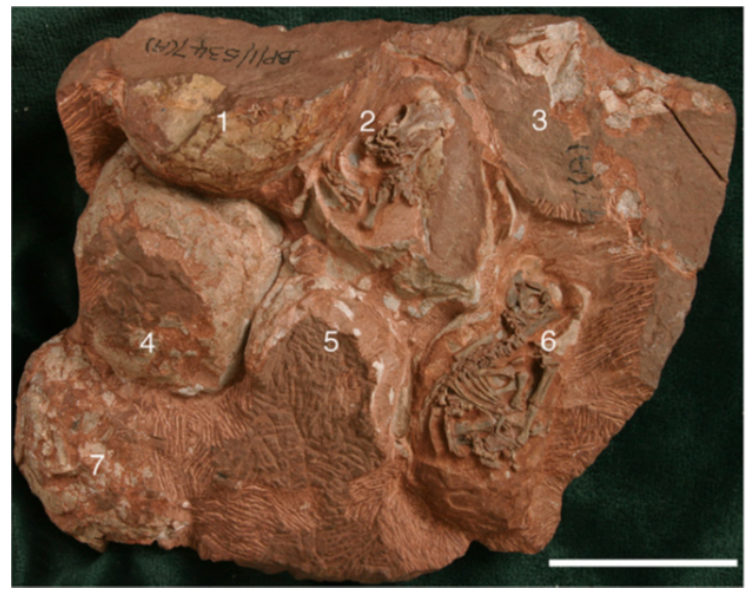

Figure 29. Massospondylus egg clutch, indicating the presence of two exposed skeletons; parts of 7 eggs (numbered) are preserved in this block. The clutch of Massospondylus carinatus eggs was discovered in 1976 in the Golden Gate Highland National Park, South Africa. Early Jurassic Period 200 - 183 million years ago (Scale bar, 5 cm) [From [83], PNAS material excluded from the Creative Commons license].

above Osteohistologists examine bones of various individuals that cover the whole span of developmental stages.

The bone traditionally used for the examination is the femur, but other bones have been shown to be equally or even more effective in some taxa [87]. The polished sections of the bones are examined under a microscope, where lines similar to tree rings can be seen. Aging is estimated by counting the total growth lines within elements. The lines (see Figure 30) probably represent periods of deceleration or possible cessation of tissue deposition and are therefore called lines of arrested growth (LAGs), [88]. The regions with high vascularity between the rings are known as zones and represent periods of dynamic growth (for a detailed analysis see Reid [89]).

It is believed that growth lines are formed annually. This is supported by the fact that the lines are structurally analogous to those found in other clades with which Dinosauria shared a common ancestry, such as Actinopterygia (ray-finned fish), Amphibia (amphibians), Lepidosauria (tuatara and squamates) and Crocodylia (crocodilians), where several studies have established their annual genesis. Furthermore, other studies have indicated that the amount of bone tissue deposited between dinosaur growth lines conforms with an annual genesis. The line spacing is also consistent with an annual genesis, with the widths becoming progressively smaller as the growth progresses [87]. It should be noted that the interpretation that each LAG corresponds to one year of growth is still debated [88]. Other methods of estimating the growth rate are also used, such as the type of primary (appositional) bone tissue that specifies the total range of growth rate [89].

\subsection{Estimated Lifespan and Growth Rates of Dinosaurs}

Depending on the assumptions and models used, various estimates were made 


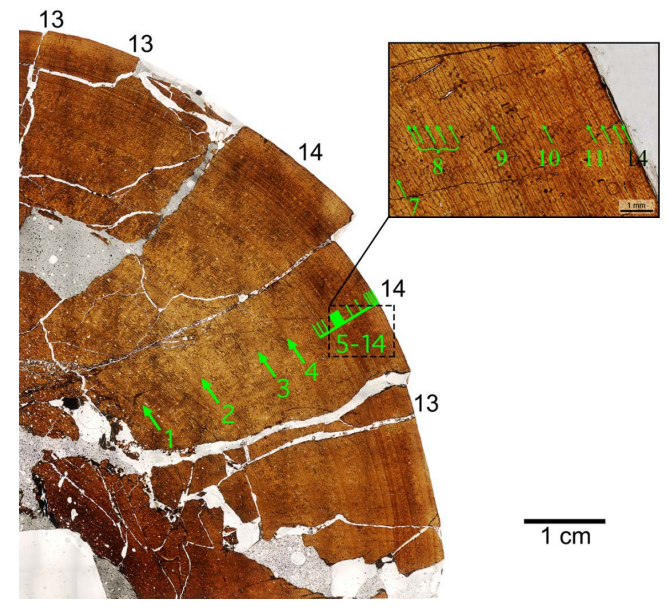

Figure 30. Tibial cross-section of a Brachylophosaurin Hadrosaur. The numbered arrows and tick marks identify the lines of arrested growth (LAGs) that are counted to age this specimen. The numbers around the circumference of the cross-section indicate the number of LAGs preserved in the bone. In the square box there is an enlargement of the area shown in the main figure, showing the LAGs [90].

about the lifespan of the dinosaurs. Current research estimates that very small theropods, such as Shuvuuia, lived 3 - 4 years, small-to-medium sized dinosaurs, such as Syntarsus and Massospondylus, lived 7 - 15 years, and large dinosaurs, such as Albertosaurus and Tyrannosaurus, lived 24 - 30 years. The giant sauropods, such as Brachiosaurus and Bothriospondylus lived for over 50 years. There is currently no reliable evidence that any dinosaur lived for more than a century, according to Erickson [87].

Erickson et al. [91] quantified growth rates for a group of dinosaurs for various lineages and size diversity for the clade and used regression analysis to describe the results. Their study estimated that dinosaurs show sigmoidal growth curves (Figure 31(a)), similar to those of other vertebrates, but their growth rate relative to body mass is unique. The authors concluded that all dinosaurs grew at faster rates than the primitive condition observed in extant reptiles. Small dinosaurs grew at fairly rapid rates, similar to those of marsupials, but large species reached rates, similar to those of eutherian mammals and precocial birds. The growth of giant sauropods was comparable to that of whales of analogous size (Figure 31(b)). It should be noted here that the above study was criticized by Myhrvold [88], and the authors followed with corrections and supplementary information [92].

\subsection{Dinosaur Diet and Feeding}

As is well known, all living organisms (except plants that metabolize dead matter), exploit the energy that results from the "killing and eating" of plants or animals on Earth, the "planet of death". Dinosaurs too, were either herbivorous or carnivorous. As mentioned in sub-Section 3.8, Ornithischians and Sauropodomorphs were the herbivorous dinosaur lineages, while the Saurischian theropods were carnivorous. Some species could also be omnivorous [95]. 


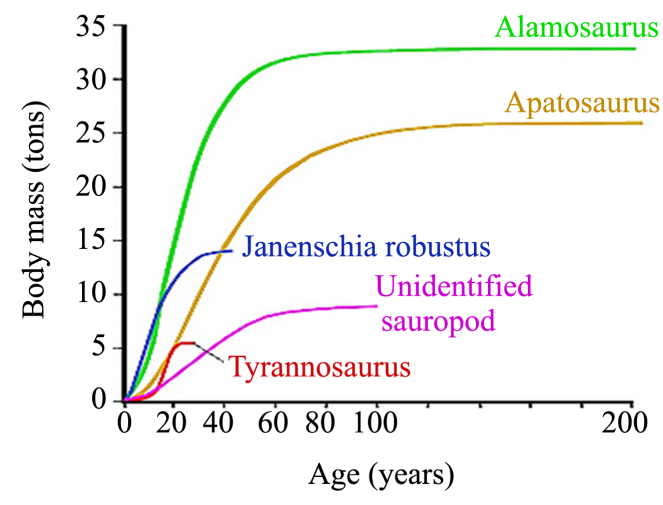

(a)

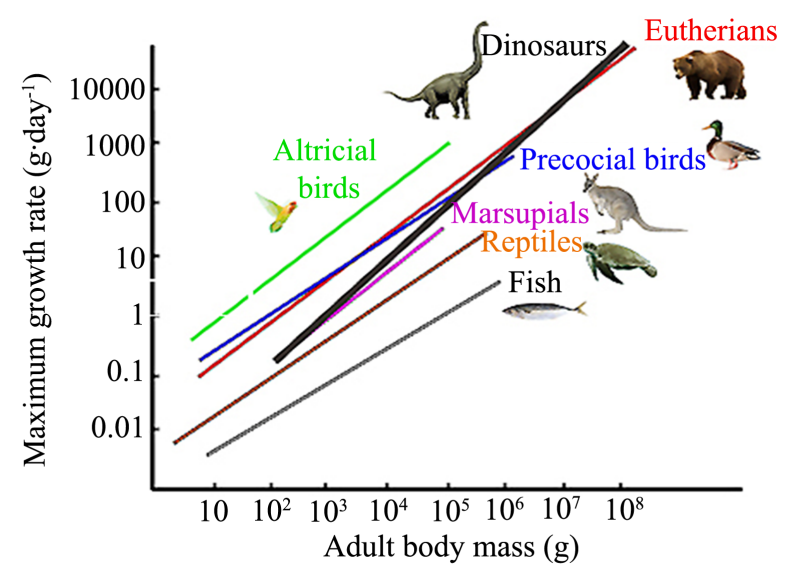

(b)

Figure 31. (a) Sigmoidal growth curves for Alamosaurus, Apatosaurus, Janenschia robustus, and Unidentified sauropod (from [93]) and Tyrannosaurus (from [94]) showing the relationship of body mass to Age. (b) Adult body mass lines versus growth rate for dinosaurs (thick line), compared to other animals (see [91]) indicating that non-avian dinosaurs grew more rapidly than extant reptiles and were most likely endothermic (Notes: Precocial birds are the species in which newborn are relatively mature and mobile from the moment of hatching, whilst newborn Altricial birds are helpless and need long-term care. Eutherians are mammals in which the placentals provide oxygen and nutrients to the fetus and carry away fetal waste products to give birth to well-developed young). 


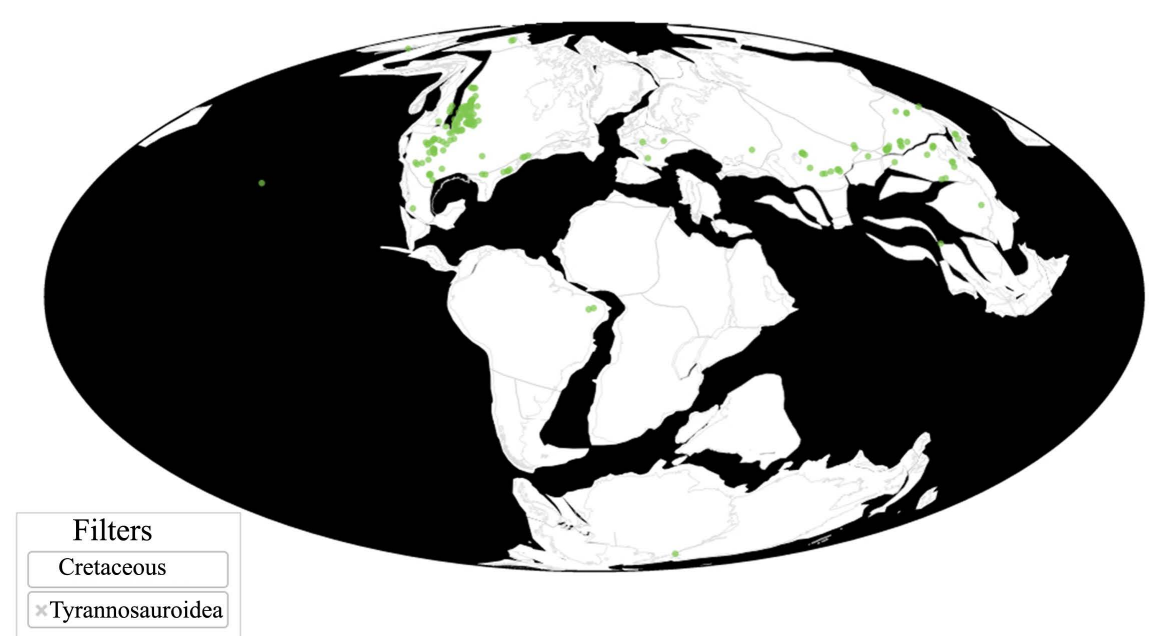

Figure 32. The distribution of Tyrannosauroidea during the Cretaceous period. Palaeomap produced by the online PBDB Navigator 1.0 [106].

3) Fossilworks [107], a Gateway to the Paleobiology Database, where one can search for fossil collection records, fossil organisms, pictures of fossils, published references, the classifications of taxa in groups, stratigraphic units, time scales and time intervals.

There are also online reliable sources, like [108], that can give many interesting details about dinosaurs, as for instance that Seismosaurus was the largest dinosaur by length $(42.7 \mathrm{~m})$ and Micropachycephalosaurus the smallest $(0.51 \mathrm{~m})$, Argentinosaurus was the heaviest (99.8 tons), and so on.

\section{Conclusions}

Paleontology is the science that studies life on earth, its evolution into various life forms and their possible relationships, the interpretation of fossilized remains and the restoration of prehistoric creatures and much more. In the latter act, specialized scientists play a role in providing support to paleontologists in describing and interpreting fossils and creating drawings, 3D sculptures and, more recently, computer animations for museum exhibitions, etc. Presentation of Paleontology themes and dinosaur reconstructions is also used for pleasure, as the subject allows considerable amounts of imagination and freedom to enter created scenes. Dinosaurs, in particular, attract the most interest because of their diversity in peculiar forms and usually because of their size.

The paper has covered various issues, as follows:

1) Important knowledge on various topics of Paleontology and Dinosaurs in particular, in order to give an impression of the time scale of life on earth, its evolution and diversity, climatic conditions, environment, etc.

2) Interpretation of scientific nomenclature, drawings and meanings.

3) Illustration of how scientists extract information from bones, tracks, eggs, embryos and other remains.

The paper, having covered the important topics related to Paleontology and 
Dinosaurs, can serve as a short guide that gives all the necessary knowledge in a comprehensible and compressed form. Further study can allow one to obtain a deeper insight and appreciation for any particular subject of Paleontology.

Paleontology still has many open-ended questions to answer, and these can only be resolved over time as more field information emerges. Many discussions continue on important topics such as (for example): 1) whether some small dinosaur species may be juveniles of larger species, 2) if long-necked sauropods naturally kept their necks horizontal, 3) what caused the dinosaurs to evolve in a specific way, and many more.

Much more knowledge is required on specific topics, such as general posture, feeding habits, existing environment and plants, skeletal, muscular and skin details, and a lot more. These need to be covered in future publications.

\section{Conflicts of Interest}

The authors declare no conflicts of interest regarding the publication of this paper.

\section{References}

[1] Dixon, D. (2008) The World Encyclopedia of Dinosaurs and Prehistoric Creatures. Lorenz Books, London, UK.

[2] Norman, D. (1994) Prehistoric Life-The Rise of the Vertebrates. Boxtree Ltd., London.

[3] Dixon, D., Cox, B., Savage, R.J.G. and Gardiner, B. (1992) The Macmillan Illustrated Encyclopaedia of Dinosaurs and Prehistoric Animals. Collier Books, Macmillan Publishing Company, New York.

[4] Fastovsky, D.E. and Weishampel, D.B. (2009) Dinosaurs: A Concise Natural History. Cambridge University Press, Cambridge. https://doi.org/10.1017/CBO9780511805189

[5] Swisher, C.C. (1997) Geologic Time. In: Eds. Currie, P.J. and Padian, K. Encyclopedia of Dinosaurs, Academic Press, Cambridge, 273-276.

[6] Eberth, A.D. (1997) Radiometric Dating. In: Currie, P.J. and Padian, K., Eds., Encyclopedia of Dinosaurs, Academic Press, Cambridge, 623-626.

[7] Lucas, S.G. (1997) Biostratigraphy. In: Eds. Currie, P.J. and Padian, K., Eds., Encyclopedia of Dinosaurs, Academic Press, Cambridge, 65-68.

[8] Cohen, K.M., Harper, D.A.T. and Gibbard, P.L. (2021) ICS International Chronostratigraphic Chart v2021/07. International Commission on Stratigraphy, International Union of Geological Sciences (IUGS), Paris. https://www.stratigraphy.org

[9] Darwin, C. (1859) Index: On the Origin of Species. John Murray, London. https://en.wikisource.org/wiki/Index:Origin_of_Species_1859_facsimile.djvu

[10] University of California, Museum of Palaeontology's Understanding Evolution (2021).

https://evolution.berkeley.edu/evolibrary/search/imagedetail.php?id=251\&topic_id $=$ \&keywords $=$ phylogeny

[11] Banerjee, S. (Ed.) (2011) Dinosaurs a Visual Encyclopedia. Dorling Kindersley Publishing Ltd., London, UK.

[12] Gould, S. (1994) The Evolution of Life on the Earth. Scientific American. 
[13] Lambert, D. (Ed.) (2003) Encyclopedia of Dinosaurs and Prehistoric Life. Dorling Kindersley Publishers Ltd., London, UK.

[14] Deep Time Maps (2021). Colorado Plateau Geosystems ${ }^{\mathrm{Tm}}$, Inc., Dublin, OH, USA. http://cpgeosystems.com

[15] National Science Foundation (2010) Scientists Find Signs of "Snowball Earth" Amidst Early Animal Evolution. http://www.nsf.gov/news/news_images.jsp?cntn_id=116410\&org=NSF

[16] Sahney, S. and Benton, M.J. (2008) Recovery from the Most Profound Mass Extinction of All Time. Proceedings of the Royal Society B: Biological Sciences, 275, 759-765. https://doi.org/10.1098/rspb.2007.1370

[17] Cao, W., Zahirovic, S., Flament, N., Williams, S., Golonka, J. and Müller, R. D. (2017) Improving Global Paleogeography since the Late Paleozoic Using Paleobiology. Biogeosciences, 14, 5425-5439. https://doi.org/10.5194/bg-14-5425-2017

[18] Azam, D. (2019, September 5) GPlates 2.2 Software and Data Sets. EarthByte Project AuScope National Collaborative Research Infrastructure (NCRIS). http://www.earthbyte.org/gplates-2-2-software-and-data-sets/

[19] Scotese C.R. (n.d.) PALEOMAP Project. http://www.scotese.com

[20] Dubiel, R., Parrish, J., Parrish, M. and Good, S. (1991) The Pangaean MegamonsoonEvidence from the Upper Triassic Chinle Formation Colorado Plateau. PALAIOS, 6, 347-370. https://doi.org/10.2307/3514963

[21] Preto, N., Kustatscher, E. and Wignall, P.B. (2010) Triassic Climates-State of the Art and Perspectives. Palaeogeography, Palaeoclimatology, Palaeoecology, 290, 1-10. https://doi.org/10.1016/j.palaeo.2010.03.015

[22] Tanner, L.H., Lucas, S.G. and Chapman, M.G. (2004) Assessing the Record and Causes of Late Triassic Extinctions. Earth-Science Reviews, 65, 103-139. https://doi.org/10.1016/S0012-8252(03)00082-5

[23] Brusatte, S.L., Benton M.J., Ruta, M. and Lloyd, G.T. (2008) The First 50 Myr of Dinosaur Evolution: Macroevolutionary Pattern and Morphological Disparity. Biology Letters, 4, 733-736. https://doi.org/10.1098/rsbl.2008.0441

[24] Rafferty, J.P. (Ed.) (2010) The Mesozoic Era: Age of Dinosaurs (The Geologic History of Earth). Britannica Educational Publishing, Newcastle upon Tyne, UK.

[25] Tattersall, I. (2010) Paleontology. A Brief History of Life. Templeton Press, West Conshohocken.

[26] Alvarez, L.W., Alvarez, W., Asaro, F. and Michael, H.V. (1980) Extraterrestrial Cause for the Cretaceous-Tertiary Extinction. Science 208, 1095-1108. https://doi.org/10.1126/science.208.4448.1095

[27] Bakker, R.T. (1986) The Dinosaur Heresies. William Morrow and Company, Inc., New York, 446.

[28] Schulte, P., Alegret, L., Arenillas, I., et al. (2010) The Chicxulub Asteroid Impact and Mass Extinction at the Cretaceous-Paleogene Boundary. Science, 327, 1214-1218. https://doi.org/10.1126/science.1177265

[29] Voosen, P. (2019, May 22) A 500-Million-Year Survey of Earth's Climate Reveals Dire Warning for Humanity. Science. https://doi.org/10.1126/science.aay1323 https://www.sciencemag.org/news/2019/05/500-million-year-survey-earths-climatereveals-dire-warning-humanity

[30] Scotese, C.R. (n.d.) PALEOMAP Project/Climate History. http://www.scotese.com/climate.htm

[31] Dayrat, B. (2005) Ancestor-Descendant Relationships and the Reconstruction of the 
Tree of Life. Paleobiology, 31, 347-353.

https://doi.org/10.1666/0094-8373(2005)031[0347:ARATRO]2.0.CO;2

[32] Whitlock, J.A. (2010) Paleoecology and Systematics of Diplodocoid Sauropods. Doctoral Dissertation, University of Michigan, Ann Arbor.

[33] Balanoff, A.M., Bever, G.S. and Ikejiri, T. (2010) The Braincase of Apatosaurus (Dinosauria: Sauropoda) Based on Computed Tomography of a New Specimen with Comments on Variation and Evolution in Sauropod Neuroanatomy. American $\mathrm{Mu}$ seum Novitates, 3677, 1-32. https://doi.org/10.1206/591.1

[34] Kardong, K.V. (2010) Vertebrates: Comparative Anatomy, Function, Evolution. 6th Edition, McGraw-Hill, New York.

[35] Gosselin-Ildari, A. (2006) Pongo Pygmaeus, Orangutan, Duke University. DigiMorph. http://www.digimorph.org/specimens/Pongo_pygmaeus/

[36] American Museum of Natural History (2011) Educator's Guide, The World's Largest Dinosaurs.

https://www.google.com/url?sa=t\&rct=j\&q=\&esrc=s\&source=web\&cd=\&ved=2ahU KEwjcjO_byN7zAhUECmMBHaPTDzUQFnoECAMQAQ\&url=https\%3A\%2F\%2F www.amnh.org\%2Fcontent\%2Fdownload\%2F58475\%2F944479\%2Fversion\%2F4\%2 Ffile\%2Fworlds_largest_dino_educators_guide.pdf\&usg=AOvVaw2hOobOXI-DH4 4vbpnF8pmw

[37] National Museum of Natural History (2014) Skeleton of Irritator Challenger Carrying a Pterosaur in Its Mouth, Rio de Janeiro, Brazil.

[38] Wilson, J.A. (1999) A Nomenclature for Vertebral Laminae in Sauropods and Other Saurischian Dinosaurs. Journal of Vertebrate Paleontology, 19, 639-653. https://doi.org/10.1080/02724634.1999.10011178

[39] Osborn, H.F. (1906) Tyrannosaurus, Upper Cretaceous Carnivorous Dinosaur (Second Communication). Bulletin of the American Museum of Natural History, 22, 281-296 and Plate 31.

[40] Osborn, H.F. and Mook C.C. (1921) Camarasaurus, Amphicoelias and Other Sauropods of Cope. Memoirs of the American Museum of Natural History, new ser., v. 3., 247-387 and Plates 60-85.

[41] Claessens, L.P. (2004) Dinosaur Gastralia; Origin, Morphology, and Function. Journal of Vertebrate Paleontology, 24, 89-106. https://doi.org/10.1671/A1116-8

[42] Yates, A.M. and Vasconcelos, C.C. (2005) Furcula-Like Clavicles in the Prosauropod Dinosaur Massospondylus. Journal of Vertebrate Paleontology, 25, 466-468. https://doi.org/10.1671/0272-4634(2005)025[0466:FCITPD]2.0.CO;2

[43] Simon, R.I. (1978) Minerals Found in Fossils: A Literature Survey. Rocks \& Minerals, 53, 16-24. https://doi.org/10.1080/00357529.1978.11764737

[44] Seeley, H.G. (1887) On the Classification of the Fossil Animals Commonly Named Dinosauria. Proceedings of the Royal Society of London, 43, 165-171. https://doi.org/10.1098/rspl.1887.0117 http://rspl.royalsocietypublishing.org/content/43/258-265/165

[45] Wilson, J.A., Marsicano, C.A. and Smith, R.M.H. (2009) Dynamic Locomotor Capabilities Revealed by Early Dinosaur Trackmakers from Southern Africa. PLoS ONE, 4, Article ID: e7331. https://doi.org/10.1371/journal.pone.0007331

[46] Padian, K. (1997) Quadrupedality. In: Currie, P.J. and Padian, K., Eds., Encyclopedia of Dinosaurs, Academic Press, Cambridge, 619-622.

[47] Paul, G.S. (2010) The Princeton Field Guide to Dinosaurs. Princeton University Press, Princeton. https://doi.org/10.1515/9781400836154 
[48] Lockley, M. (1991) Tracking Dinosaurs. Cambridge University Press, Cambridge, New York, Port Chester, Melbourne, Sydney.

[49] Thulborn, T. (1990) Dinosaur Tracks. Chapman and Hall, London.

[50] Alexander, R.M. (1976) Estimates of Speeds of Dinosaurs. Nature, 261, 129-130. https://doi.org/10.1038/261129a0

[51] Thulborn, R.A. (1984) Preferred Gaits of Bipedal Dinosaurs. Alcheringa, 8, 243-252. https://doi.org/10.1080/03115518408618947

[52] Henderson, D. (2003) Footprints, Trackways, and Hip Heights of Bipedal Dinosaurs-Testing Hip Height Predictions with Computer Models. Ichnos, 10, 99-114. https://doi.org/10.1080/10420940390257914

[53] Thulborn, R.A. and Wade M. (1984) Dinosaur Trackways in the Queensland. Memoirs Queensland Museum, 21, 413-517.

[54] Kim, J.Y. and Lockley, M.G. (2013) Review of Dinosaur Tail Traces. Ichnos, 20, 129-141. https://doi.org/10.1080/10420940.2013.817405

[55] Milner, A.R.C., Harris, J.D., Martin G., Lockley, J., Kirkland, I. and Matthews, N.A. (2009) Bird-Like Anatomy, Posture, and Behavior Revealed by an Early Jurassic Theropod Dinosaur Resting Trace. PLoS ONE, 4, Article No. e4591. https://doi.org/10.1371/journal.pone.0004591

[56] Barnes-Svarney, P. and Svarney, T. (2010) The Handy Dinosaur Answer Book. Visible Ink Press, Wayne County, 147.

[57] Thomas, D.A and Farlow, J.O. (1997) Tracking a Dinosaur Attack. Scientific American, 277, 74-79. https://www.jstor.org/stable/10.2307/24996045 https://doi.org/10.1038/scientificamerican1297-74

[58] Fiorillo, A., Hasiotis, S. and Kobayashi, Y. (2014) Herd Structure in Late Cretaceous Polar Dinosaurs: A Remarkable New Dinosaur Tracksite, Denali National Park, Alaska, USA. Geology, 42, 719-722. https://doi.org/10.1130/G35740.1

[59] Padian, K. (Ed.) (1988) The Beginning of the Age of Dinosaurs: Faunal Change across the Triassic-Jurassic Boundary. Cambridge University Press, Cambridge.

[60] Smith, J. and Farlow, J. (2003) Osteometric Approaches to Track-Maker Assignment for the Newark Supergroup Ichnogenera Grallator, Anchisauripus, and Eubrontes. In: LeTourneau, P. and Olsen, P., Eds., The Great Rift Valleys of Pangea in Eastern North America, Vol. 2: Sedimentology, Stratigraphy, and Paleontology, Columbia University Press, New York, 273-292.

[61] Farlow, J.O., O’Brien, M., Kuban, G.J., Dattilo, B.F., Bates, K.T., Falkingham, P.L., Piñuela, L., Rose, A., Freels, A., Kumagai, C., Libben, C., Smith, J. and Whitcraft, J. (2012) Dinosaur Tracksites of the Paluxy River Valley (Glen Rose Formation, Lower Cretaceous), Dinosaur Valley State Park, Somervell County, Texas. Proceedings of the 5 th International Symposium about Dinosaur Palaeontology and their Environment, Burgos, 2011, 41-69.

[62] Lockley, M.G. and Lucas, S.G. (Eds.) (2014) Fossil Footprints of Western North America: Bulletin 62 (Vol. 62). New Mexico Museum of Natural History and Science, Albuquerque.

[63] Meyer, C.A., Marty, D. and Belvedere, M. (2018) Titanosaur Trackways from the Late Cretaceous el molino Formation of Bolivia (Cal Orck'o, Sucre). Annales Societatis Geologorum Poloniae, 88, 223-241. https://doi.org/10.14241/asgp.2018.018

[64] Malkani, M.S. (2019) Recently Discovered Basilosaurid, Baluchithere Rhinoceros, Horses, Sea Cow, Proboscidean, Eucrocodile, Pterosaurs, Plesiosaur, Fishes, Inver- 
tebrates and Wood Fossils, Tracks and Trackways of Dinosaurs from Pakistan; Comparison of Recognized Four Titanosaur Taxa of Indo-Pakistan with Madagascar. Open Journal of Geology, 9, 919-955. https://doi.org/10.4236/ojg.2019.912098

[65] Fisher, P.E., Russell, D.A., Stoskopf, M.K., Barrick, R.E., Hammer, M. and Kuzmitz, A.A. (2000) Cardiovascular Evidence for an Intermediate or Higher Metabolic Rate in an Ornithischian Dinosaur. Science 288, 503-505.

https://doi.org/10.1126/science.288.5465.503

[66] Cleland, T.P., Schroeter, E.R., Zamdborg, L., Zheng, W., Lee, J.E., Tran, J.C., Bern, M., Duncan, M.B., Lebleu, V.S., Ahlf, D.R. and Thomas, P.M. (2015) Mass Spectrometry and Antibody-Based Characterization of Blood Vessels from Brachylophosaurus canadensis. Journal of Proteome Research, 14, 5252-5262. https://doi.org/10.1021/acs.jproteome.5b00675

[67] Schweitzer, M.H., Zheng, W., Organ, C.L., Avci, R., Suo, Z., Freimark, L.M., Lebleu, V.S., Duncan, M.B., Vander Heiden, M.G., Neveu, J.M. and Lane, W.S. (2009) Biomolecular Characterization and Protein Sequences of the Campanian hadrosaur B. Canadensis. Science, 324, 626-631. https://doi.org/10.1126/science.1165069

[68] Bertazzo, S., Maidment, S.C.R., Kallepitis C., Fearn, S., Stevens, M.M and Xie, H.N. (2015) Fibres and Cellular Structures Preserved in 75-Million-Year-Old Dinosaur Specimens. Nature Communications, 6, Article No. 7352.

https://doi.org/10.1038/ncomms8352

[69] Manning, P.L., Morris, P.M., McMahon, A., Jones, E., Gize, A., Macquaker, J.H., Wolff, G., Thompson, A., Marshall, J., Taylor, K.G. and Lyson, T. (2009) Mineralized Soft-Tissue Structure and Chemistry in a Mummified Hadrosaur from the Hell Creek Formation, North Dakota (USA). Proceedings of the Royal Society of London B: Biological Sciences, 276, 3429-3437.

https://doi.org/10.1098/rspb.2009.0812

[70] Lindgren, J., Kaddumi, H.F. and Polcyn, M.J. (2013) Soft Tissue Preservation in a Fossil Marine Lizard with a Bilobed Tail Fin. Nature Communications, 4, Article No. 2423. https://doi.org/10.1038/ncomms3423

[71] Armitage, M.H. (2016) Preservation of Triceratops horridus Tissue Cells from the Hell Creek Formation, MT. Microscopy Today, 24, 18-23.

https://doi.org/10.1017/S1551929515001133

[72] Schweitzer, M.H., Wittmeyer, J.L., Horner J.R. and Toporski, J.K. (2005) Soft-Tissue Vessels and Cellular Preservation in Tyrannosaurus rex. Science, 307, 1952-1955. https://doi.org/10.1126/science.1108397

[73] Lee, Y.C., Chiang, C.C., Huang, P.Y., Chung, C.Y., Huang, T.D., Wang, C.C., Chen, C.I., Chang, R.S., Liao, C.H. and Reisz, R.R. (2017) Evidence of Preserved Collagen in an Early Jurassic Sauropodomorph Dinosaur Revealed by Synchrotron FTIR Microspectroscopy. Nature Communications, 8, Article No. 14220.

https://doi.org/10.1038/ncomms14220

[74] Schweitzer, M.H., Zheng W., Cleland, T.P., Goodwin, M.B., Boatman, E., Theil, E., Marcus, M.A. and Fakra, S.C. (2014) A Role for Iron and Oxygen Chemistry in Preserving Soft Tissues, Cells and Molecules from Deep Time. Proceedings of the Royal Society of London B: Biological Sciences, 281, Article ID: 20132741. https://doi.org/10.1098/rspb.2013.2741

[75] Allentoft, M.E., Collins, M., Harker, D., Haile, J., Oskam, C.L., Hale, M.L. Campos, P.F., Samaniego, J.A., Gilbert, M.T.P., Willerslev, E. and Zhang, G. (2012) The Half-Life of DNA in Bone: Measuring Decay Kinetics in 158 Dated Fossils. Proceedings of the Royal Society of London B: Biological Sciences, 279, 4724-4733. 
https://doi.org/10.1098/rspb.2012.1745

[76] Martin, A.J. (2006) Introduction to the Study of Dinosaurs. 2nd Edition, Blackwell Publishing, Hoboken.

[77] Osborn, H.F., Kaisen, P.C. and Olsen, G. (1924) Three New Theropoda, Protoceratops Zone, Central Mongolia. American Museum Novitiates, No. 144, 1-12.

[78] Dingus, L., Chiappe, L.M. and Coria, R.A. (2008) Dinosaur Eggs Discovered! Unscrambling the Clues. Twenty-First Century Books, Minneapolis MN, USA.

[79] Horner. J.R. and Makela, R. (1979) Nest of Juveniles Provides Evidence of Family Structure among Dinosaurs. Nature, 282, 296-298.

https://doi.org/10.1038/282296a0

[80] Chiappe, L.M. and Dingus, L. (2001) Walking on Eggs: The Astonishing Discovery of Thousands of Dinosaur Eggs in the Badlands of Patagonia. Scribner Publishing, New York.

[81] Vila, B. (2014) Fossil Focus: Eggs, Nests and Dinosaur Reproduction Fossil Focus. Palaeontology Online, 4, Article No. 4.

http://www.palaeontologyonline.com/articles/2014/fossil-focus-eggs-nests-dinosaur -reproduction/

[82] Varricchio, D.J., Horner, J.J. and Jackson, F.D. (2002) Embryos and Eggs for the Cretaceous Theropod Dinosaur Troodon formosus. Journal of Vertebrate Paleontology, 22, 564-576. https://doi.org/10.1671/0272-4634(2002)022[0564:EAEFTC]2.0.CO;2

[83] Reisz, R.R., Evans, D.C., Roberts, E.M., Sues, H.D. and Yates, A.M. (2012) Oldest Known Dinosaurian Nesting Site and Reproductive Biology of the Early Jurassic Sauropodomorph Massospondylus. Proceedings of the National Academy of Sciences of the United States of America, 109, 2428-2433. https://doi.org/10.1073/pnas.1109385109

[84] Carpenter, K. (1999) Eggs, Nests, and Baby Dinosaurs: A Look at Dinosaur Reproduction. Indiana University Press, Bloomington.

[85] Simon, D.J., Varricchio, D.J., Jin, X. and Robison, S.F. (2018) Microstructural Overlap of Macroelongatoolithus Eggs from Asia and North America expands the Occurrence of Colossal Oviraptorosaurs. Journal of Vertebrate Paleontology, 38, Article No. e1553046. https://doi.org/10.1080/02724634.2018.1553046

[86] Erickson, G.M., Zelenitsky, D.K., Kay, D.I. and Norell, M.A. (2017) Dinosaur Incubation Periods Directly Determined from Growth-Line Counts in Embryonic Teeth Show Reptilian-Grade Development. Proceedings of the National Academy of Sciences of the United States of America, 114, 540-545.

https://doi.org/10.1073/pnas.1613716114

[87] Erickson, G.M. (2005) Assessing Dinosaur Growth Patterns: A Microscopic Revolution. Trends in Ecology and Evolution, 20, 677-684. https://doi.org/10.1016/j.tree.2005.08.012

[88] Myhrvold, N.P. (2013) Revisiting the Estimation of Dinosaur Growth Rates. PLoS ONE, 8, Article ID: e81917. https://doi.org/10.1371/journal.pone.0081917

[89] Reid, R.E.H. (1997) Dinosauria Physiology: The Case for "Intermediate" Dinosaurs. In: Farlow, J.O. and Brett-Surman, M.K., Eds., The Complete Dinosaur, Indiana University Press, Bloomington, 449-473.

[90] Fowler, E.A.F. and Horner, J.R. (2015) A New Brachylophosaurin Hadrosaur (Dinosauria: Ornithischia) with an Intermediate Nasal Crest from the Campanian Judith River Formation of Northcentral Montana. PLoS ONE, 10, Article ID: e0141304. 
https://doi.org/10.1371/journal.pone.0141304

[91] Erickson, G.M., Curry Rogers, K. and Yerby, S.A. (2001) Dinosaurian Growth Patterns and Rapid Avian Growth Rates. Nature, 412, 428-433.

https://doi.org/10.1038/35086558

[92] Erickson, G.M., Curry Rogers, K. and Yerby, S.A. (2015) Correction: Corrigendum: Dinosaurian Growth Patterns and Rapid Avian Growth Rates. Nature, 531, 538. https://doi.org/10.1038/nature16488

[93] Lehman, T.M. and Woodward, H.N. (2008) Modeling Growth Rates for Sauropod Dinosaurs. Paleobiology, 34, 264-281. https://doi.org/10.1666/0094-8373(2008)034[0264:MGRFSD]2.0.CO;2

[94] Erickson, G.M., Makovicky, P.J., Currie, P.J., Norell, M.A., Yerby, S.A. and Brochu, C.A. (2004) Gigantism and Comparative Life-History Parameters of Tyrannosaurid Dinosaurs. Nature, 430, 772-775. https://doi.org/10.1038/nature02699

[95] Barrett, P.M., Butler, R.J. and Nesbitt, S.J. (2010) The Roles of Herbivory and Omnivory in Early Dinosaur Evolution. Earth and Environmental Science Transactions of the Royal Society of Edinburgh, 101, 383-396. https://doi.org/10.1017/S1755691011020111

[96] Stevens, K.A. and Parrish, J.M. (2005) Neck Posture, Dentition, and Feeding Strategies in Jurassic Sauropod Dinosaurs. In: Tidwell, V. and Carpenter, K., Eds. Thunderlizards: The Sauropodomorph Dinosaurs. Indianan University Press, Bloomington, 212-232.

[97] Whitlock, J.A. (2011) Inferences of Diplodocoid (Sauropoda: Dinosauria) Feeding Behavior from Snout Shape and Microwear Analyses. PLoS ONE, 6, Article ID: e18304. https://doi.org/10.1371/journal.pone.0018304

[98] Nabavizadeh, A. (2020) New Reconstruction of Cranial Musculature in Ornithischian Dinosaurs: Implications for Feeding Mechanisms and Buccal Anatomy. The Anatomical Record, 303, 347-362. https://doi.org/10.1002/ar.23988

[99] Chin, K. (2007) The Paleobiological Implications of Herbivorous Dinosaur Coprolites from the Upper Cretaceous Two Medicine Formation of Montana: Why Eat Wood? PALAIOS, 22, 554-566. https://doi.org/10.2110/palo.2006.p06-087r

[100] Jacobsen, A.R. (1998) Feeding Behaviour of Carnivorous Dinosaurs as Determined by Tooth Marks on Dinosaur Bones. Historical Biology, 13, 17-26. https://doi.org/10.1080/08912969809386569

[101] Hungerbühler, A. (1998) Taphonomy of the Prosauropod Dinosaur Sellosaurus, and Its Implications for Carnivore Faunas and Feeding Habits in the Late Triassic. Palaeogeography, Palaeoclimatology, Palaeoecology, 143, 1-29. https://doi.org/10.1016/S0031-0182(98)00074-1

[102] Brown, C.M., Greenwood, D.R., Kalyniuk, J.E., Braman, D.R., Henderson, D.M., Greenwood, C.L. and Basinger, J.F. (2020) Dietary Palaeoecology of an Early Cretaceous Armoured Dinosaur (Ornithischia; Nodosauridae) Based on Floral Analysis of Stomach Contents. Royal Society Open Science, 7, Article ID: 200305. https://doi.org/10.1098/rsos.200305

[103] Wings, O. and Sander, P.M. (2007) No Gastric Mill in Sauropod Dinosaurs: New Evidence from Analysis of Gastrolith Mass and Function in Ostriches. Proceedings of the Royal Society B: Biological SCIENCES, 274, 635-640. https://doi.org/10.1098/rspb.2006.3763

[104] Cloudsley-Thompson, J.L. (2005) Herbivorous Dinosaurs. In: Ecology and Behaviour of Mesozoic Reptiles, Springer, Berlin, Heidelberg, 149-169. 
[105] Paleobiology Database (2021) CC BY 4.0 International. https://paleobiodb.org/\#/

[106] PBDB Navigator (2021). https://paleobiodb.org/navigator/

[107] Fossilworks (2021) Fossilworks, a Gateway to the Paleobiology Database. http://fossilworks.org/?a=collectionSearchForm\&type=view

[108] The Dino Database (2021) Dinosaur Records. http://www.dinodatabase.com/dinorcds03.asp 